\title{
Effect of particle morphology, compaction, and confinement on the high strain rate behavior of sand
}

Keywords: granular materials, high strain rate, Long Split Hopkinson Pressure Bar (LSHPB), impact loading.

Authors: F. De Cola ${ }^{1 *}$, A. Pellegrino ${ }^{1}$, C. Glößner ${ }^{3}$, D. Penumadu², N. Petrinic ${ }^{1}$.

Affiliations:

- $\quad{ }^{1}$ Department of Engineering Science, Solid Mechanics Group, University of Oxford, OX5 1PF, United Kingdom

- ${ }^{2}$ Civil and Environmental Engineering Department and Joint Institute of Advanced Materials, University of Tennessee, Knoxville, TN, USA 37936

- $\quad{ }^{3}$ Fraunhofer Institute - Ernst Mach Institute, Kandern, 79400, Germany

*Corresponding author: francesco.decola@eng.ox.ac.uk, +44 (0)1865 613452

\section{ABSTRACT}

The effect of grain shape, size distribution, intergranular friction, confinement, and initial compaction state on the high strain rate compressive mechanical response of sand is quantified using Long Split Hopkinson Pressure Bar (LSHPB) experiments, generating up to $1.1 \mathrm{~ms}$ long load pulses. This allowed the dynamic characterisation of different types of sand until full compaction (lowest initial void ratio) at different strain rates. The effect of the grain morphology and size on the dynamic compressive mechanical response of sand is assessed by conducting experiments on three types of sand: Ottawa Sand with quasi-spherical grains, Euroquartz Siligran with subangular grains and Q-Rok with polyhedral grain shape are considered in this study. The adoption of rigid (Ti64) and deformable (Latex) sand containers allowed for quasi-uniaxial strain and quasi-uniaxial stress conditions to be achieved respectively. Additionally, the effect of intergranular friction was studied, for the first time in literature, by employing polymer coated Euroquartz sand. Appropriate procedures for the preparation of samples at different representative initial consolidation states are utilized to achieve realistic range of naturally occurring formations of granular assembly from loose to dense state. The results identify material and confining sample state parameters which have 
significant effect on the mechanical response of sand at high strain rates and their interdependency for future integration into rate dependent constitutive models.

\section{INTRODUCTION}

Geo-materials like sands and soils are widely used in civil engineering and they are as such of significant relevance to defence applications.

Most of these applications are particularly related to the high potential of granular materials to attenuate shock loading, disperse momentum and dissipate kinetic energy when subjected to rapidly applied loads such as those arising from earthquakes [1], explosions [2, 3], or projectile penetration [4].

The extensively increasing adoption of granular materials in highly dynamic applications requires better characterisation of their mechanical response at high rates of strain.

Geo-materials have been sporadically characterised at high strain rate in the last decades due to the difficulties associated with their complex nature and with the complexity of the experimental techniques required to fulfil this task.

The Split Hopkinson Pressure Bar is the experimental apparatus commonly adopted for the evaluation of the high strain rate behaviour of solid materials $[5,6,7]$. A detailed description of the theory behind the analysis of data obtained by means of SHPB apparatus can be found in $[8]$.

High strain rate experiments are considered valid only when dynamic force equilibrium conditions are achieved within the sample. Materials like sand are highly discontinuous media, characterised by very low wave propagation speed [3,9]. When the stress wave propagation speed is low and the loading rate is very high, dynamic equilibrium conditions may not be achieved during the entire duration of the test. For this last reason, over the years, the original SHPB setup underwent many changes and improvements, aiming to extend its range of applications to all those materials characterised by low wave propagation speed. One of the methods adopted to facilitate dynamic equilibrium consists in interposing a sacrificial, highly deformable material between projectile and input bar $[10,11,12]$. During the impact, the deformation of the sacrificial material shapes the incident stress wave, modifying its rising time. Most of the existing publications adopt this approach to ensure stress equilibrium and improve the strain rate constancy during the test. However, one drawback connected to this method is the substantial increment of the rise time of the incident stress wave, with a consequent reduction of the maximum achievable strain rate at low strains. 
The work presented in this manuscript was carried out by using a $1 \mathrm{~mm}$ thick cardboard shim $\left(436 \mathrm{~g} / \mathrm{m}^{2}\right)$ to reduce the transmitted Pochhammer-Chree oscillations [11] caused by the highfrequency oscillation and by the coupling between axial and radial displacements in the sample (Poisson effect). Acceptable equilibrium conditions and constant strain rates were achieved by controlling the dimensions of the specimen as described in [13].

Moreover, the experiments in this work were conducted by adopting a Long-SHPB apparatus [14]. Details of this set up are described in Section 2.1. The main peculiarity of this setup is the longer length of the projectile $(2.7 \mathrm{~m})$, which influences the duration of the incident pulse [8]. An SHPB with a projectile of $500 \mathrm{~mm}$ generates a pulse with a duration of about $0.2 \mathrm{~ms}$ while a more than five times longer pulse $(1.1 \mathrm{~ms})$ can be obtained using this new configuration. The adoption of this setup enabled longer pulses of higher magnitude to be applied to the sample under consideration, hence allowing for the achievement of higher strains than what currently existing in the literature.

The mechanical behaviour of sand is strongly influenced by many parameters such as initial consolidation state, confining pressure, strain rate, intergranular friction and grain shape [15]. These effects need to be addressed.

Several researchers investigated the mechanical behaviour of dry sand. Most of their publications provided information on the overall behaviour of certain sands rather than the results of systematic parametric studies aimed at understanding the effects of each key parameter (i.e., void ratio, saturation levels, strain rates, etc.) and their combination upon the mechanical response of sands. A comprehensive review of most of the high strain rate results on sand and relevant experimental techniques is presented in [16].

The current literature mainly addresses the mechanical response of dry sand specimens within rigid containers subjected to impact loading using conventional SHPB [17, 18, 19]. Moreover, the response of nearly-unconfined sand has not been investigated much. For instance, a detailed study of the compressive response of dry sand by adopting a modified SHPB was presented in [20]. This work showed the effects of two initial consolidation states, of the strain rate and of the type of confinement on the mechanical response of one specific kind of sand. Felice et al. [21] conducted experiments, by using a classical SHPB, on wet clayey sand, varying water contents, dimensions of the samples and loading rates.

However, there are neither detailed studies on the effect of microscale properties such as grain shape and inter-grain friction nor were researches aiming to appreciate the effects of the 
combination and interference of these parameters on the high strain rate mechanical response of sand. The current study wants to fill this gap, by presenting a comprehensive high strain rate characterisation of sand that addresses the influence of grain shape, intergranular friction, confining pressure, initial consolidation state, strain rate and possible combination of these on the stress-strain behaviour of granular materials. Moreover, the adoption of a Long Split Hopkinson Pressure Bar apparatus allows for the achievement of longer pulses duration and higher consolidation states.

\section{EXPERIMENTAL SETUP AND MATERIAL}

\subsection{THE LSHPB SETUP}

The Long Split Hopkinson Pressure Bar adopted for the experiments conducted in this study included input and output bars made of Ti64, $2.8 \mathrm{~m}$ long and $20 \mathrm{~mm}$ in diameter. Both bars were supported by low-friction polymeric circular bearings (with a support distance of $40 \mathrm{~cm}$ ), in order to avoid sagging, buckling and any undesired lateral movement, as well as to ensure the alignment between bars and specimen. The schematic of the adopted setup is shown in Fig. 1.

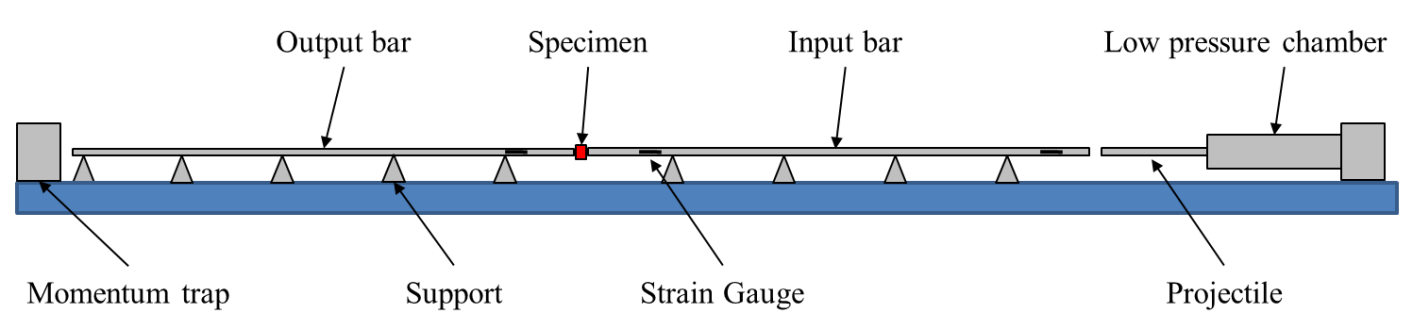

Fig. 1 Long Split Hopkinson Bar Setup

The adoption of a longer projectile enabled longer test duration, hence allowing for the analysis of a wider spectrum of strains with respect to what existed in literature.

Gerlach et al. [14] presented a clear comparison between the pulses achieved using a similar setup and the classical ones.

A length of the projectile equal to the length of the input bar inevitably leads to the superimposition of incident and reflected elastic stress waves into the input bar at the gauge location. A data analysis procedure, based on the method of characteristics and on D'Alambert's solution of wave equations, is used to calculate the magnitude of forward and backward travelling strain waves $(\alpha(x, t)$ and $\beta(x, t))$ as functions of position and time. This 
enables the calculation of total longitudinal elastic stress and particle velocity in any selected cross section of the bar as follows:

$$
\begin{gathered}
\sigma(x, t)=E(\alpha(x, t)+\beta(x, t)) \\
v(x, t)=-\frac{E}{\rho c}(\alpha(x, t)-\beta(x, t))
\end{gathered}
$$

where $E$ represents the Young's modulus of the bar material, $\rho$ its density and $c$ its elastic wave speed.

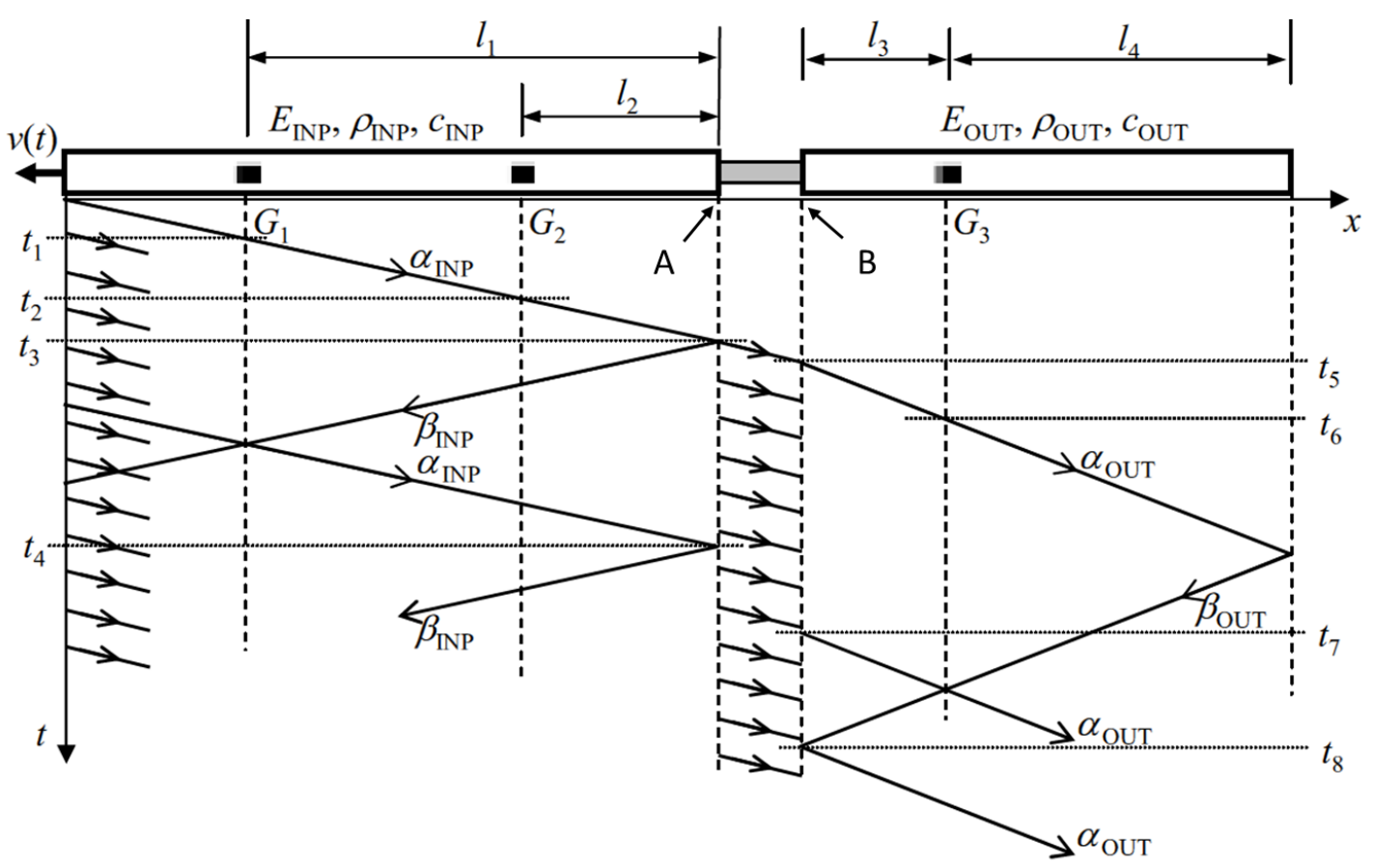

Fig. 2: Lagrangian diagram for 1D wave propagation in a LSHB

Fig. 2 shows the Lagrangian diagram for the 1D wave propagation in a LSHB having two strain gauges G1 and G2 in the input section (INP) of the bar, at a distance $l_{1}$ and $l_{2}$ from the specimen, and one strain gauge G3 in the output section (OUT) of the bar, at a distance $l_{3}$.

The velocities of particles and stresses in the cross sections at the interfaces between bars and specimens (A and B in Fig. 2) can be evaluated from the readings of the three strain gauges by computing magnitudes of forward and backward travelling waves using the following routine:

$$
\begin{array}{cc}
t<t_{4} & \left\{\begin{array}{c}
\alpha\left(x_{A}, t\right)=\varepsilon\left(x_{G_{1}}, t-\left(t_{3}-t_{1}\right)\right) \\
\beta\left(x_{A}, t\right)=\varepsilon\left(x_{G_{2}}, t+\left(t_{3}-t_{2}\right)\right)-\varepsilon\left(x_{G_{1}}, t+\left(t_{3}-t_{2}\right)-\left(t_{2}-t_{1}\right)\right)
\end{array}\right. \\
t \geq t_{4} & \left\{\begin{array}{c}
\alpha\left(x_{A}, t\right)=\varepsilon\left(x_{G_{1}}, t-\left(t_{3}-t_{1}\right)\right)-\beta\left(x_{A}, t-\left(t_{4}-t_{3}\right)\right) \\
\beta\left(x_{A}, t\right)=\varepsilon\left(x_{G_{2}}, t+\left(t_{3}-t_{2}\right)\right)-\left\{\varepsilon\left(x_{G_{1}}, t+\left(t_{3}-t_{2}\right)-\left(t_{2}-t_{1}\right)\right)-\beta\left(x_{A}, t-2\left(t_{2}-t_{1}\right)\right)\right\}
\end{array}\right. \\
t<t_{7} & \left\{\begin{array}{c}
\alpha\left(x_{B}, t\right)=\varepsilon\left(x_{G_{3}}, t+\left(t_{6}-t_{5}\right)\right) \\
\beta\left(x_{A}, t\right)=0
\end{array}\right.
\end{array}
$$




$$
\begin{array}{lc}
t_{7} \leq t<t_{8} & \left\{\begin{array}{r}
\alpha\left(x_{B}, t\right)=\varepsilon\left(x_{G_{3}}, t+\left(t_{6}-t_{5}\right)\right)+\alpha\left(x_{B}, t-\left(t_{7}-t_{5}\right)\right) \\
\beta\left(x_{A}, t\right)=0
\end{array}\right. \\
t \geq t_{8} & \left\{\begin{array}{r}
\alpha\left(x_{B}, t\right)=\varepsilon\left(x_{G_{3}}, t+\left(t_{6}-t_{5}\right)\right)+\alpha\left(x_{B}, t-\left(t_{7}-t_{5}\right)\right) \\
\beta\left(x_{A}, t\right)=-\alpha\left(x_{B}, t-\left(t_{8}-t_{5}\right)\right)
\end{array}\right.
\end{array}
$$

The computed values of $\alpha(x, t)$ and $\beta(x, t)$ were substituted in eq. (1) and (2) to define particles velocities and stresses at the interfaces.

However, the results obtained from the SHPB experiments were considered valid only when the sample was in dynamic equilibrium conditions. Generally, the achievement of constant strain rate and dynamic equilibrium conditions are enhanced by reducing the length of the sample. However, a too short specimen might introduce uncertainties in the homogeneity of granular media $[13,22]$.

The length of the sand specimens adopted in this research was designed to improve the repeatability of the results, following the procedure presented in [13].

\subsection{SAND MATERIALS AND LATERAL CONFINEMENTS}

\subsubsection{Ottawa, Q-Rok and Euroquartz Sand}

Three types of Crystalline Silica sand were tested: Ottawa sand with round grain shape, Euroquartz Siligran - trocken 0.125-0.71 mm with sub-rounded grains and Q-Rok sand with polyhedral grain shapes.

Ottawa and Q-Rok sand were obtained from US Silica, Berkeley Springs, West Virginia. Their mineralogy is presented in Table 1 .

Table 1 Mineralogy of the Ottawa and Q-Rok sand

\begin{tabular}{|l|l|}
\hline COMPONENT & $\%$ \\
\hline Quartz & 99.7 \\
\hline Aluminum Oxide & $<0.1$ \\
\hline Iron Oxide & $<0.1$ \\
\hline Titanium Oxide & $<0.1$ \\
\hline
\end{tabular}

Both Ottawa and Q-Rok sand passed \#20 sieve (sieve opening $=0.84 \mathrm{~mm}$ ) but were retained on \#30 sieve (sieve opening = $0.6 \mathrm{~mm}$ ). The measured size distributions of Ottawa and Q-Rok sand are reported in Fig. 3. 


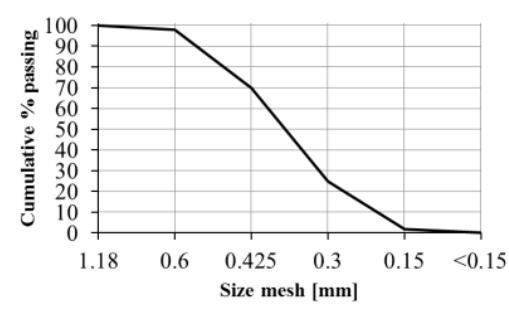

a)

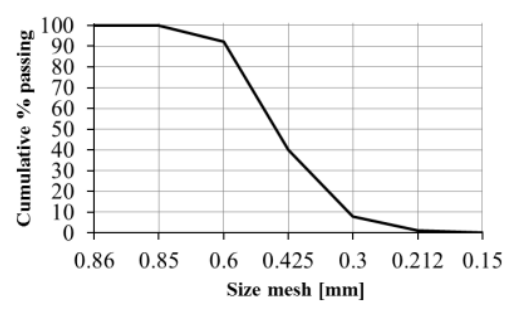

b)

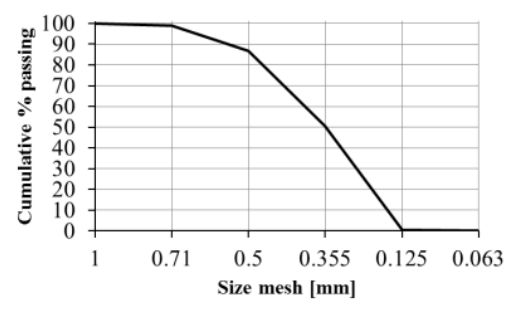

c)

Fig. 3 Size distribution of (a) Ottawa, (b) Q-Rok, and (c) Euroquartz sand

The specific gravity of both sands was $2.65 \mathrm{~g} / \mathrm{cm}^{3}$ and their bulk density was equal to $1.6 \mathrm{~g} / \mathrm{cm}^{3}$. Ottawa sand is a naturally occurring sand, whilst Q-Rok sand is obtained by crushing. Their hardness is equivalent to 7 Mohs.

Euroquartz Siligran trocken sand was obtained by Euroquartz Gmbh (Germany). Table 2 shows its mineralogy.

Table 2 Mineralogy of Euroquartz sand

\begin{tabular}{|l|l|}
\hline COMPONENT & $\%$ \\
\hline Quartz & 99.6 \\
\hline Aluminum Oxide & $<0.2$ \\
\hline Iron Oxide & $<0.1$ \\
\hline Titanium Oxide & $<0.1$ \\
\hline
\end{tabular}

The Euroquartz sand passed \#18 sieve (sieve opening = $1 \mathrm{~mm}$ ) but retained on \#25 sieve (sieve opening $=0.71 \mathrm{~mm}$ ). The specific gravity of Euroquartz sand was $2.65 \mathrm{~g} / \mathrm{cm}^{3}$ and its bulk density was equal to $1.6 \mathrm{~g} / \mathrm{cm}^{3}$.

Some of the following experiments were conducted using Euroquartz sand with grains coated by a thin layer of epoxy resin. The coating itself did not modify the distribution of sizes considered in Fig. 3.

A comparison between the shapes of the three types of sand, using microscopy, is shown in Fig. 4. 


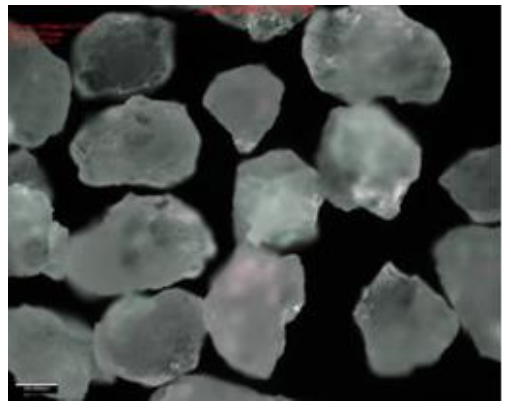

a)

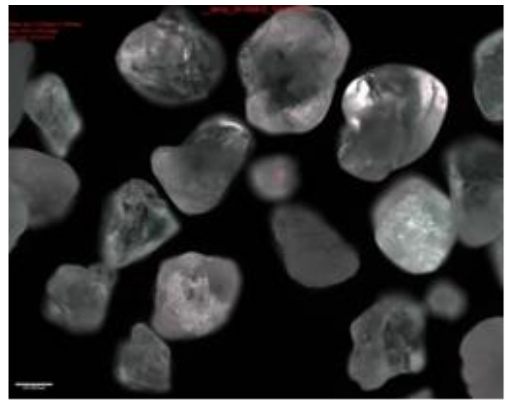

b)

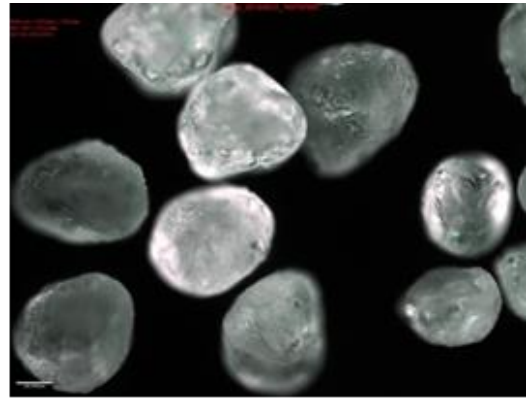

c)

Fig. 4 Comparison between the different shapes: a) Q-Rok, b) Euroquartz Siligran 0.125-0.71 and c) Ottawa sand

\subsubsection{Containers for lateral confinement of sand specimens}

Appropriate confinements were designed to allow for the preparation and positioning of representative samples of sand within the LSHPB apparatus. Two configurations were adopted to test the sand under quasi-uniaxial stress and quasi-uniaxial strain conditions:

1. Quasi-uniaxial strain condition - rigid containment. A stainless steel cylinder, of internal diameter equal to the diameter of the bars $(20 \mathrm{~mm})$, length of $120 \mathrm{~mm}$ and thickness of the walls of $5 \mathrm{~mm}$ was used as a container. The thickness was determined in order to prevent any plastic deformation of the container during compression testing (Fig. 5-a). The sand was constrained within the container using two cylindrical Ti64 anvils of diameter equal to $20 \mathrm{~mm}$ and length of $40 \mathrm{~mm}$. The material and cross section chosen for the anvils were the same of the bars to ensure mechanical impedance matching, as confirmed by calibration tests. The anvils were also used to preserve the input and output bars from indentation/erosion by sand specimens. 


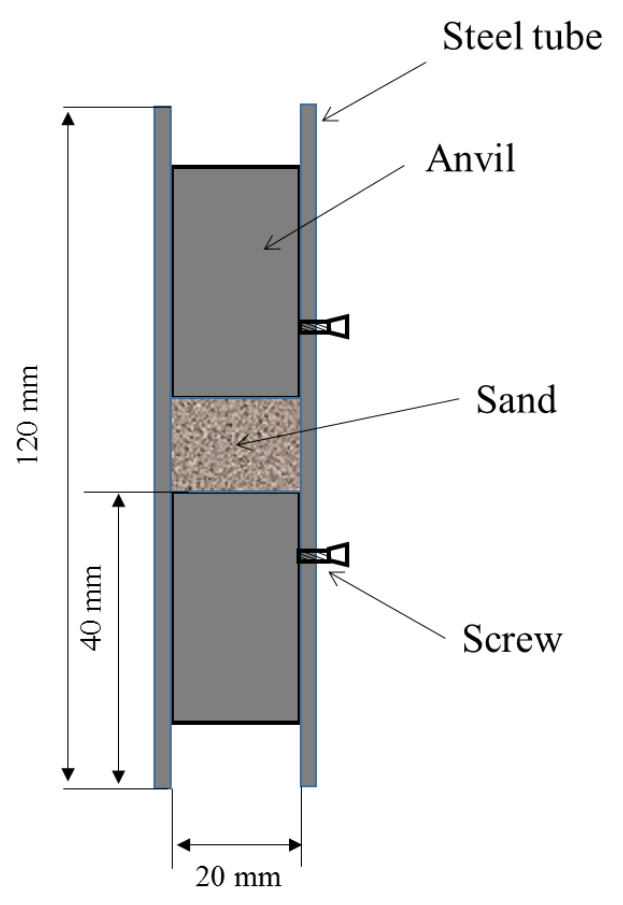

a)

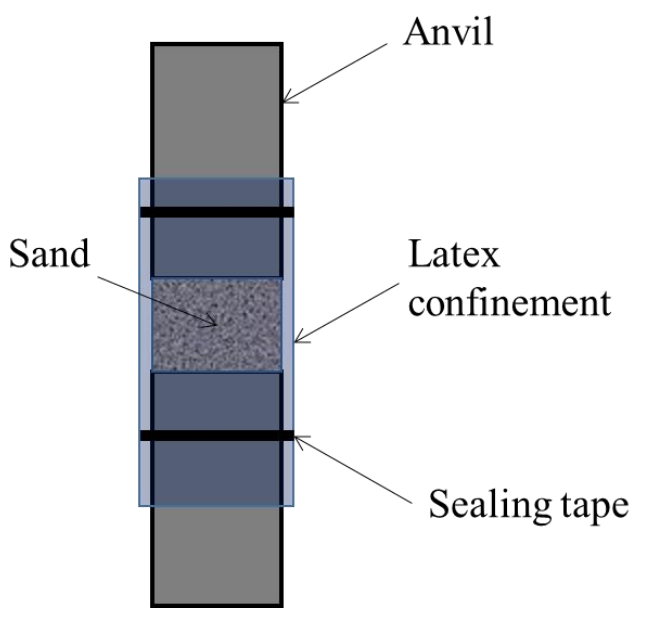

b)

Fig. 5 Schematic of (a) stainless steel confinement and (b) latex confinement

2. Quasi-uniaxial stress conditions - deformable containment. Deformable latex confinements of diameter corresponding to the diameter of the bars and length equal to $10 \mathrm{~mm}$ were used as a container. Also in this case, the sand was constrained using two Ti64 anvils as described above. The latex cylinder was sealed to the two anvils by means of adhesive tape. Fig. 5-b depicts a schematic representation of the latex confinement.

Both containers were positioned within an aluminium support to keep the cylinder in position and avoid any misalignment between the two bars and the sample. The two anvils were constrained during the filling phase using two grub-screws (similarly to [23]), until the cylindrical containment was placed between the two bars, in horizontal position. The screws were removed, before the execution of the test, once anvils and bars were in contact. The grubscrews replaced any adhesives. This approach ensured the contact and alignment between bars and anvils avoiding the input signal to be affected by the presence of any interfacial material. 


\subsection{SAMPLES PREPARATION}

Most naturally occurring granular materials are random assemblies of discrete entities (grains) that interact through contacts. Their mechanical behaviour is strongly dependent on both microscopic features of the medium (grains properties) and packing properties (consolidation state) $[24,25]$. Therefore, differently from continuous materials, the control of the consolidation state is fundamental for a correct mechanical characterisation of the medium.

A measure of the consolidation state is the void ratio $(e)$, defined as the ratio between the volume of voids $V_{v}$ and the volume of solids $V_{s}$

$$
e=\frac{V_{v}}{V_{s}}
$$

Another equivalent parameter, largely adopted in soil mechanics, is the porosity $(n)$ that is defined as the ratio between the volume of voids and the total volume of the sample $V_{t o t}$

$$
n=\frac{V_{v}}{V_{t o t}}
$$

The two definitions are linked by the following:

$$
n=\frac{e}{1+e}
$$

The preparation of the sample is a crucial and delicate issue. Each test has to be representative of a fixed and reproducible consolidation state. This section presents three different consolidation procedures adopted to produce loose, intermediate and dense samples.

The values of void ratio used for the densest and loosest samples were defined according to the technique described by Lade et al. [26] and applied in X-Ray and Neutron Tomography characterization studies of sand specimens by Kim et al. [27]. Such methodology allows for the obtainment of realistic dense and loose consolidation conditions for the materials under consideration.

Both porosity and void ratio, defined in (9) and (10), can be expressed in terms of bulk density of the silica sand $\left(\rho_{s p}\right)$, total volume comprised between the two anvils $\left(V_{t o t}\right)$ and mass of sand $(m)$ poured within the container (equations (11) and (12)). 


$$
\begin{gathered}
n=100 *\left(1-\frac{V_{s}}{V_{t o t}}\right)=100 *\left(1-\frac{\frac{m}{\rho_{s p}}}{V_{t o t}}\right) \\
e=\frac{n}{1-n}
\end{gathered}
$$

The sand samples used in the present work were cylinders with $20 \mathrm{~mm}$ diameter and $6 \mathrm{~mm}$ height. These dimensions were set following the procedure detailed in [13] and define the $V_{t o t}$ occupied by the sand. Once the bulk density and the sample volume were defined, the only remaining variable was the mass of sand. The variation of the mass poured into the container allowed for the attainment of different void ratios.

\subsubsection{Preparation of dense assemblies}

Dense sand assemblies were characterised by a void ratio of 0.57 for Ottawa sand, 0.69 for QRok and 0.56 for Euroquartz sand. The total amount of sand to pour into the container was measured using precision weighing scales. This quantity of sand was divided into three equal parts and the following procedure was repeated for each of the portions.

First, the sand was poured into the container using a funnel. After that, the container was tapped five times on four diametrical points. Then, the sand was further compressed dropping ten times a weight with a fixed mass $(240 \mathrm{~g})$ from a determined height $(5 \mathrm{~cm})$ until the final required length of the specimen was obtained. As confirmed by preliminary checks through visual inspection and sieving analysis, the force applied to the sand during this process was not sufficient to trigger grains failure, thus ensuring the preservation of size distribution and shape of the grains.

\subsubsection{Preparation of intermediate assemblies}

The intermediate configuration, which corresponds to void ratios of 0.65 for Ottawa sand, 0.85 for Q-Rok and 0.72 for Euroquartz sand, was obtained via three consecutive steps. Firstly, the total amount of sand to pour in the container to achieve the given void ratio was measured using a precise set of weighing scales. This quantity of sand was poured into the container using a funnel. The funnel was then moved along the container with a constant velocity until its final height $\mathrm{L}$ was covered. Finally, the container was tapped ten times on each side on four diametrical points. 


\subsubsection{Preparation of loose assemblies}

The preparation of loose samples, corresponding to void ratios equal to 0.78 for Ottawa sand, 1 for Q-Rok and 0.8 for Euroquartz sand, was achieved in two steps. The total amount of sand was measured using a weighing scale. Then, the sand was poured into the container by means of a funnel that was moved upwards until covering the length of the container. Table 3 summarises the void ratios obtained for the three types of sand in loose, intermediate and dense configurations. Table 4, instead, summarises the weight of sand poured into the container to achieve the characteristic void ratio of each experimental configuration. The scatter in the measured void ratios was less than $1 \%$. The mass was measured with fractional uncertainty of less than $0.5 \%$.

Table 3 Void ratio for the three types of sand

\begin{tabular}{|c|c|c|c|}
\hline & $\begin{array}{l}\text { Loose } \\
\text { consolidation }\end{array}$ & $\begin{array}{l}\text { Intermediate } \\
\text { consolidation }\end{array}$ & Dense consolidation \\
\hline Ottawa & 0.78 & 0.65 & 0.57 \\
\hline Q-Rok & 1.00 & 0.85 & 0.69 \\
\hline Euroquartz & 0.80 & 0.72 & 0.56 \\
\hline
\end{tabular}

Table 4 Mass of sand poured into the containers for the three types of sand $[\mathrm{g}]$

\begin{tabular}{l|c|c|c}
\cline { 2 - 4 } & $\begin{array}{l}\text { Loose } \\
\text { consolidation }\end{array}$ & $\begin{array}{l}\text { Intermediate } \\
\text { consolidation }\end{array}$ & Dense consolidation \\
\hline Ottawa & 2.8 & 3 & 3.2 \\
Q-Rok & 2.5 & 2.7 & 3 \\
Euroquartz & 2.8 & 3 & 3.2 \\
\hline
\end{tabular}

\section{EXPERIMENTAL RESULTS}

In this section, the results of experimental characterisation of three types of sand are presented. The effects of initial consolidation state, shapes of the grains, coating, confinement, and their combination on their mechanical behaviour are considered.

Generally, four phases of compression response behaviour can be identified by observing the stress-strain curve obtained from SHPB experiments on sand specimens [28, 16], as illustrated in Fig. 6: 
Zone 1: The grains rearrange and deform elastically because the axial stress level is not high enough to exceed the static friction between individual sand grains, showing an initial elastic constrained modulus $[28,16]$. The strain measurements obtained by means of the SHPB tend, in general, to show lack of constancy in the strain rate.

Zone 2: The stress exceeds the static friction causing the rolling and sliding of the particles in the intergranular voids and the subsequent deformation of the soil skeleton. The stress-strain behaviour in this region deviates from the initial pseudo-elastic response and an apparent yield point can be detected. The values of the stress and strain corresponding to the apparent yield point $\left(\sigma_{1}, \epsilon_{1}\right)$ and to the following point of local minimum stress $\left(\sigma_{2}, \epsilon_{2}\right)$ are extensively reported in the following analysis. If the initial assembly is loose, this zone is dominated by compressive response, and for initial dense configurations, dilation plays a critical role, and in both cases particle kinematics could include translations and rotations.

Zone 3: A denser state is produced by the rearrangement of sand grains into the voids, thereby more contacts between the grains occur. Relative movements become more difficult, and a following "lock-up" is obtained.

Zone 4: At high-stress levels, grains fragmentation followed by an additional contraction in the volume of the specimen are observed. The material exhibits a higher pseudo-elastic stiffness. The point $\chi\left(\sigma_{\chi}\right.$ and $\left.\epsilon_{\chi}\right)$ is another relevant point reported in the following sections.

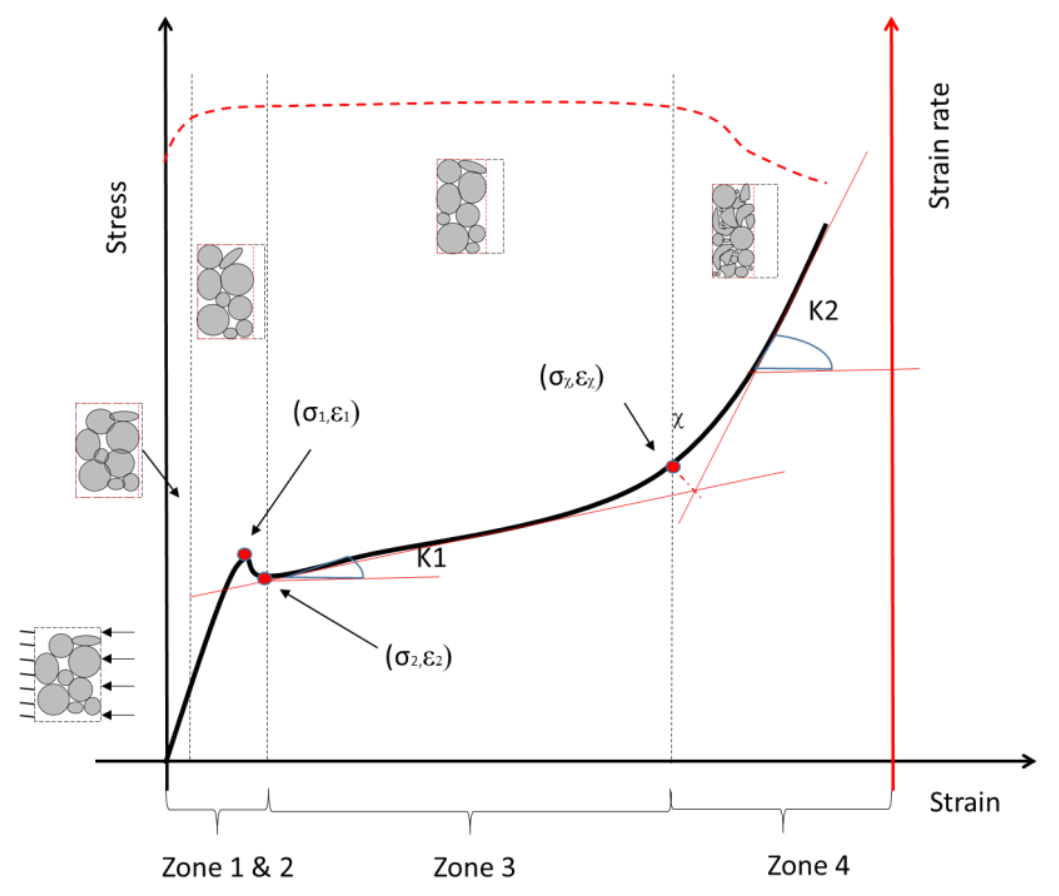

Fig. 6 Definition of the main zones of the stress-strain curve (in black) obtained during uniaxial compression tests and corresponding strain rate curve (in red); in the cartoons, the elastic deformation is represented with an overlap between grains 
The red dotted line in Fig. 6 shows the typical strain rate history obtained during uniaxial compression of sand. Thanks to the adoption of ad-hoc dimensions for the samples and bespoke pulse-shaping, dynamic equilibrium is readily achieved throughout the specimen. A constant strain rate is generally achieved for most of the test, except for the very early stages of the compression and at very high strains.

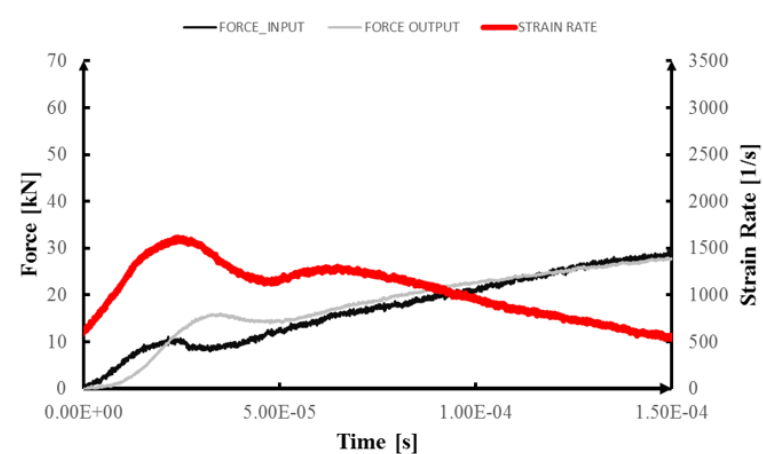

a)

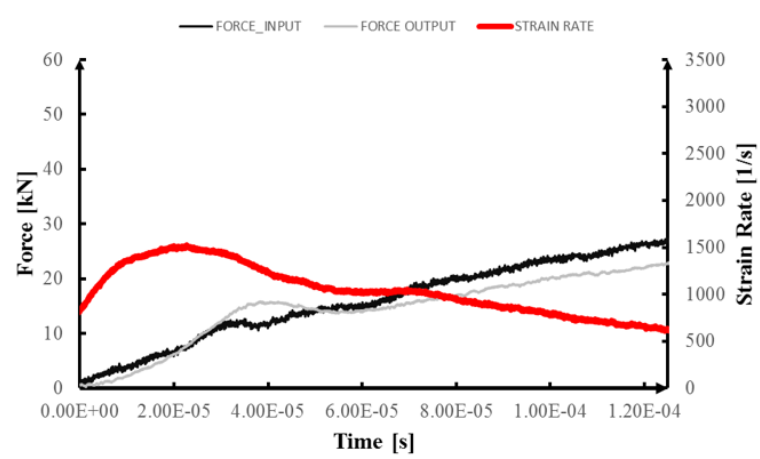

c)

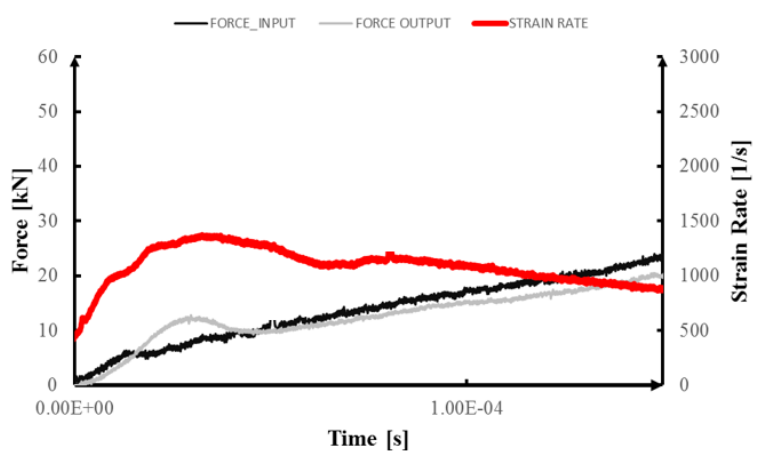

b)

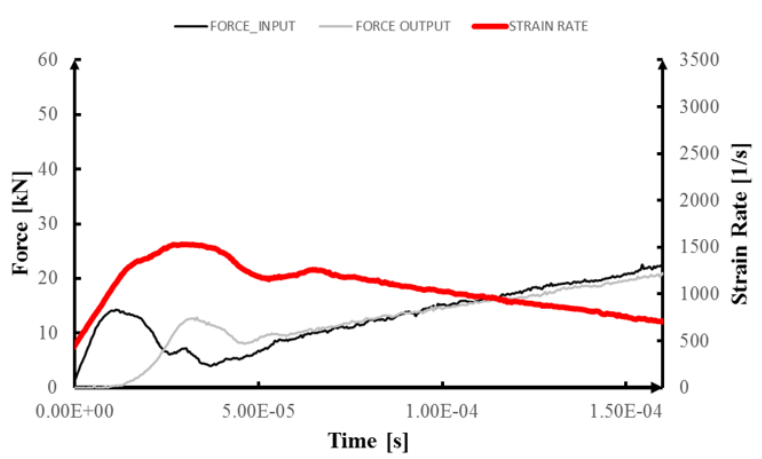

d)

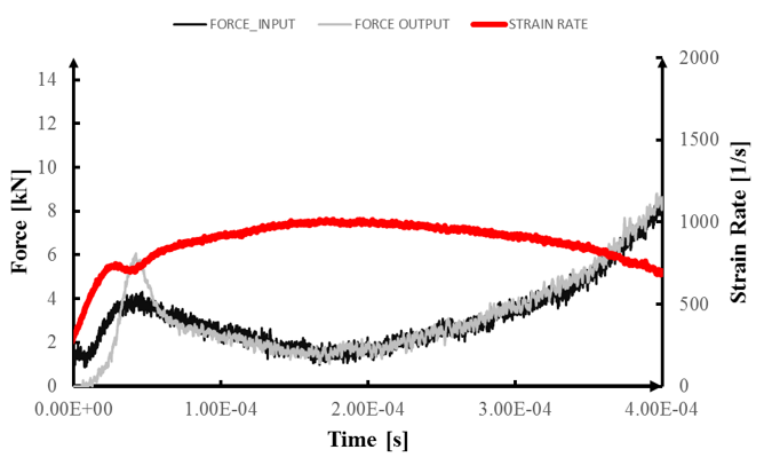

e)

Fig. 7 Examples of force equilibrium and strain rate for: (a) Ottawa dense, (b) Ottawa loose, (c) Euroquartz dense, (d) QRok dense and (e) Ottawa in deformable confinement

Examples of strain rates and force histories at the sample-bar interfaces (demonstrating the achievement of good dynamic equilibrium conditions) in different experimental configurations are shown in Fig. 7. 
The following sections also report the specific energy dissipated during deformation for all sample configurations considered in the present work. This energy was calculated as the area underlying the stress-strain curve and it is presented together with specific stress and strain values at different critical points. In particular, the total dissipated energy is split in three portions: $E_{1-2}$, equal to the specific energy dissipated in zone 1 and 2 of the stress-strain curve (Fig. 6); $E_{3}$ and $E_{4}$ corresponding respectively to the specific energy in zone 3 and 4 . This will provide additional insight into the behaviour of granular media when subjected to blast and impact loading.

A minimum number of three repeatable experiments per configuration were conducted. This number was increased to five tests per configuration when the repeatability of the results was outside the desired tolerance. For clarity, whenever appropriate, the number of individual results included in the following plots was reduced to a minimum.

\subsection{EFFECT OF THE INITIAL CONSOLIDATION STATE}

The void ratio is one of the main parameters influencing the mechanical response of granular media subjected to compressive loading. Characterising the mechanical behaviour of a granular medium without controlling its initial consolidation state would alter the determination of its response $[13,22]$.

This section shows the effect of the initial consolidation state on the mechanical behaviour of three different types of sand when loaded compressively within a stiff lateral confinement, i.e. under nearly uniaxial strain conditions. Ottawa and Q-Rok sand were compressed at two different strain rates $\left(600 \mathrm{~s}^{-1}\right.$ and $\left.1600 \mathrm{~s}^{-1}\right)$ in order to characterise the interdependence between the effects of void ratio and strain rate on their mechanical response. 


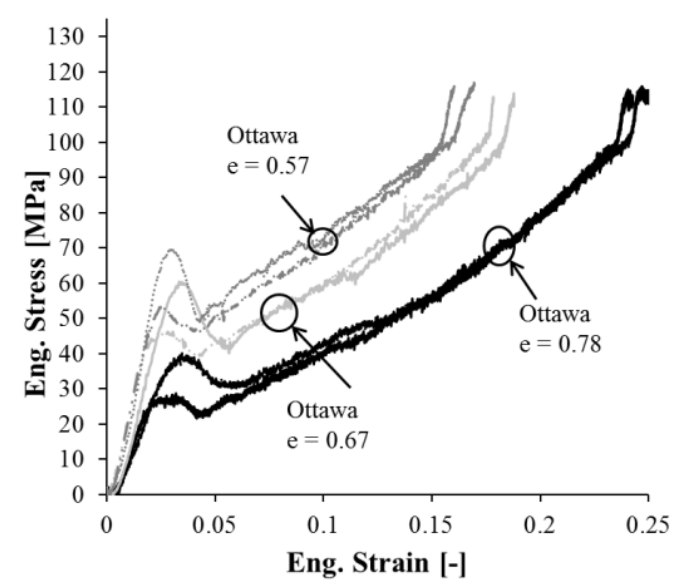

a)

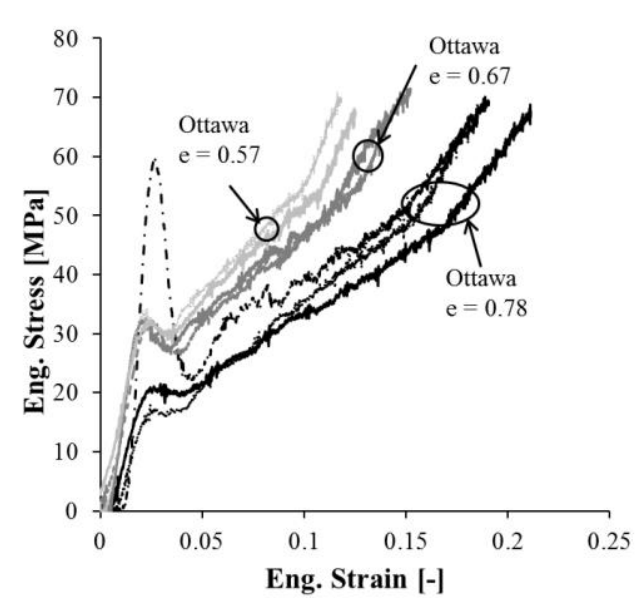

b)

Fig. 8 Effect of the initial consolidation state on Ottawa sand at (a) $1600 \mathrm{~s}^{-1}$ and (b) $600 \mathrm{~s}^{-1}$

Fig. 8-a shows how the flow stress increased with the initial density (reduction of the void ratio), showing a strong dependence of the Ottawa sand behaviour upon the initial consolidation $[23,29,16]$. This can be explained by the higher availability of voids in loose samples thus exhibiting a more compliant behaviour when compared to dense specimens. This trend persisted even at lower strain rates as deducible in Fig. 8-a and Fig. 8-b.

The effect of the initial consolidation state upon the confinement modulus is shown in Fig. 9a. The variation of the stiffness of the stress-strain curve (K1 in zone 3 of Fig. 6) with the void ratio was not unequivocal. The Ottawa sand in its initial dense consolidation state $(e=0.57)$ presented an increased stiffness when compared with the loose configuration $(e=0.78)$, but lower than the value obtained for the intermediate configurations. However, the values obtained for intermediate and dense configurations are substantially in the same range, with the small differences in the stiffness $(\approx 7.2 \%)$ probably due to the linear fitting of the data across experimental oscillations. 


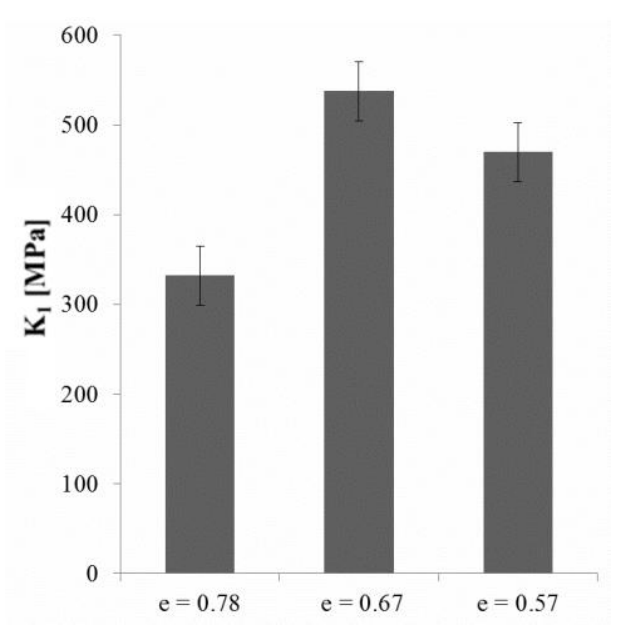

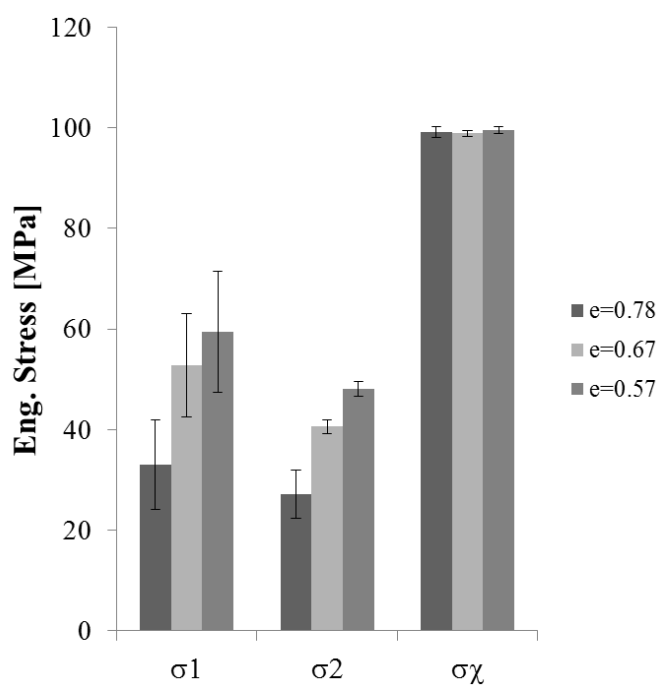

b)

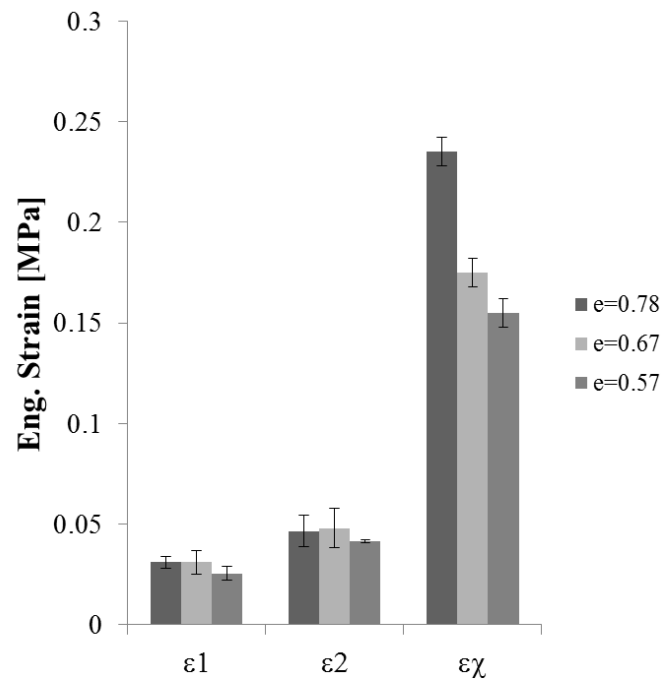

c)

Fig. 9 Confined modulus for the three initial void ratios (a), and effect of the initial consolidation state on the salient points of the stress (b) - strain (c) curves for Ottawa sand

A more explicit trend could be identified by comparing the variation of the relevant levels of stress and strain (see Fig. 6 for notations) with the consolidation state (Fig. 9-b and Fig. 9-c). The apparent yield stress $\left(\sigma_{1}\right)$ increased, as expected, with the relative initial density of the assembly, whilst the stress at the point $\chi\left(\sigma_{\chi}\right)$ appeared to be unaffected by the consolidation state. On the contrary, the effect of the initial consolidation state on the strains was evident with $\varepsilon_{\chi}$ substantially decreasing when increasing the initial compaction (i.e. larger deformations for loose samples due to the eased rearrangement of grains during compaction).

A summary of all results illustrating the effect of the initial consolidation state on the mechanical response of Q-Rok sand at strain rates of 1600 s-1 and 600 s-1 is shown in Fig.9. 


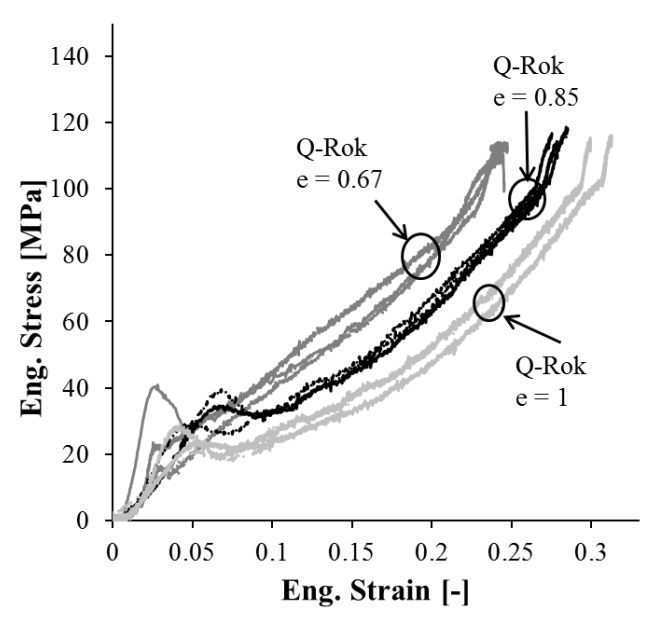

a)

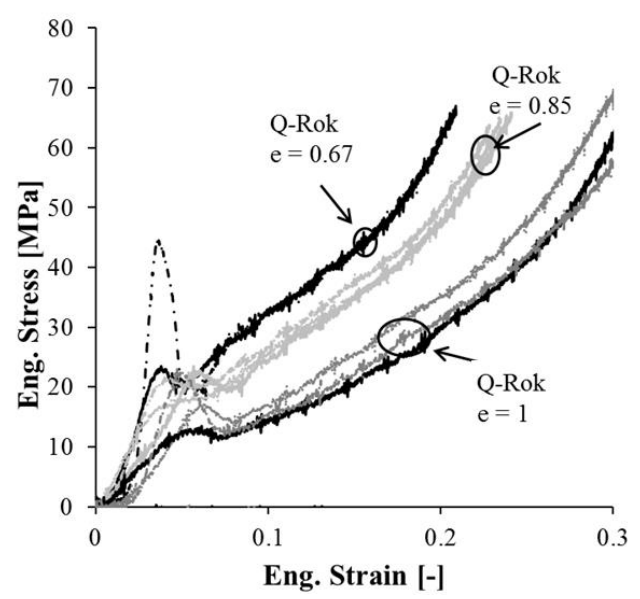

b)

Fig. 10 Effect of the initial consolidation state on Q-Rok sand at (a) $1600 \mathrm{~s}^{-1}$ and (b) $600 \mathrm{~s}^{-1}$

The effect of the relative density on the confined modulus $\left(K_{1}\right)$ was evident (Fig. 11-a). Lower relative densities (moving from $e=0.67$ to $e=1$ ) produced a substantial decrease of $\mathrm{K}_{1}$.

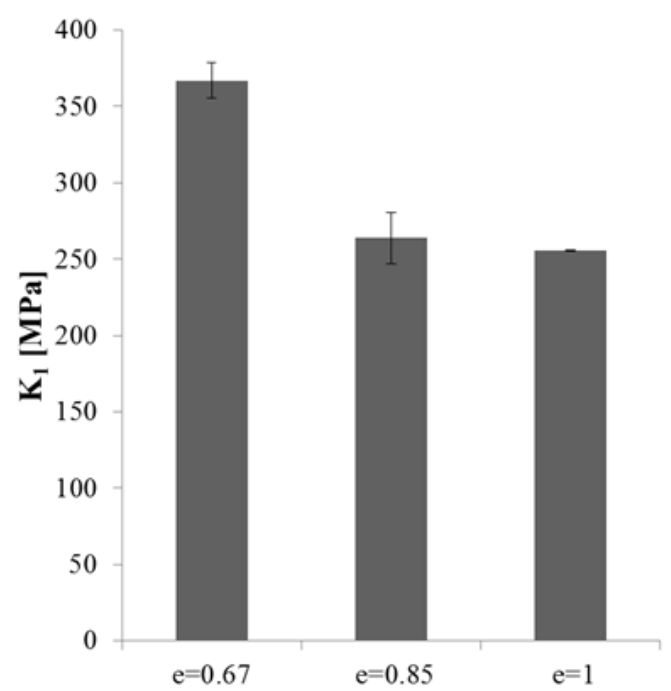

a)

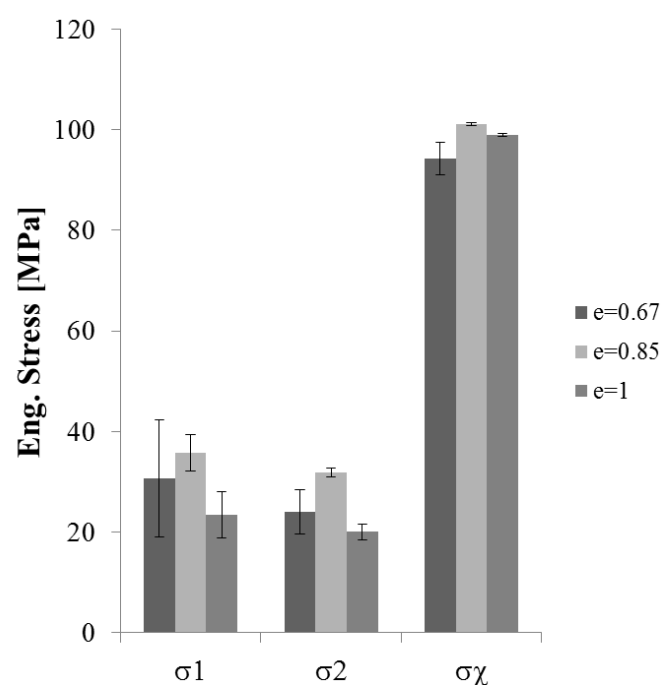

b)

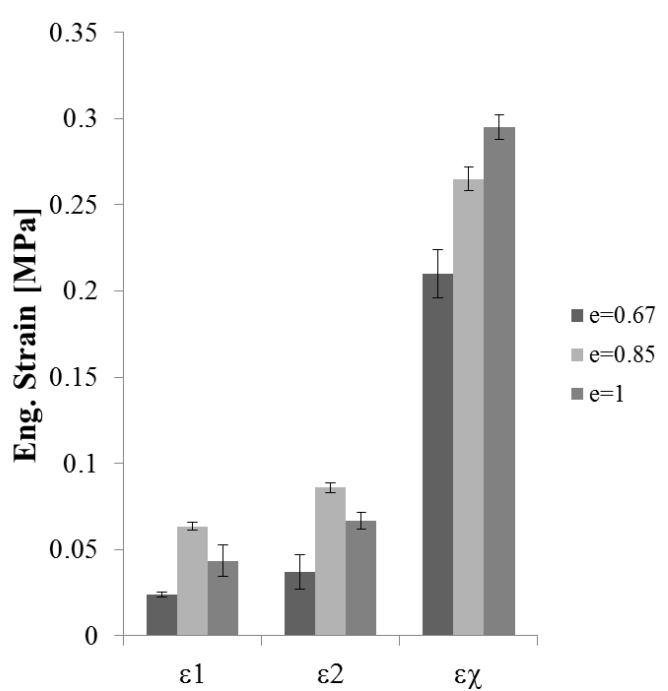

c) 
Fig. 11 Confined modulus for the three initial void ratios (a) and effect of the initial consolidation state on the salient points of the stress (b) - strain (c) curves for Q-Rok sand

The comparison of the measured values of stress and strain around the apparent yield point did not allow for a straightforward conclusion on the effect of consolidation state for Q-Rok sand (Fig. 11-b and Fig. 11-c). This was mainly due to the oscillations in the mechanical response present at low strains, common in SHPB experiments. However, the flow stress was clearly higher in sands with lower void ratios. The effect on the points $\chi$ was similar to the one observed for Ottawa sand: also for Q-Rok, the point $\chi$ moved to higher values of strain (higher $\varepsilon_{\chi}$ ) for lower compaction states. The stress $\sigma_{\chi}$, instead, remained nearly constant. The effect of the consolidation state on the stress-strain curves did not change at lower strain rates, as it is evident in Fig. 10.

The response of Ottawa sand in a loose configuration (Fig. 8-a) and Q-Rok in its more densely packed state at strain rates of about $1600 \mathrm{~s}^{-1}$ (Fig. 10-a) showed very similar results. This observation denotes the concurrent effects of initial consolidation state and grain morphology (spherical for Ottawa and polyhedral for Q-Rok) on the mechanical response. Additional results showing exclusively the effect of the shape of the grains on the stress-strain curves are presented in Section 3.2

Lastly, the effect of the consolidation state upon the response of Euroquartz sand at high strain rate $\left(1600 \mathrm{~s}^{-1}\right)$ is presented in Fig. 12.

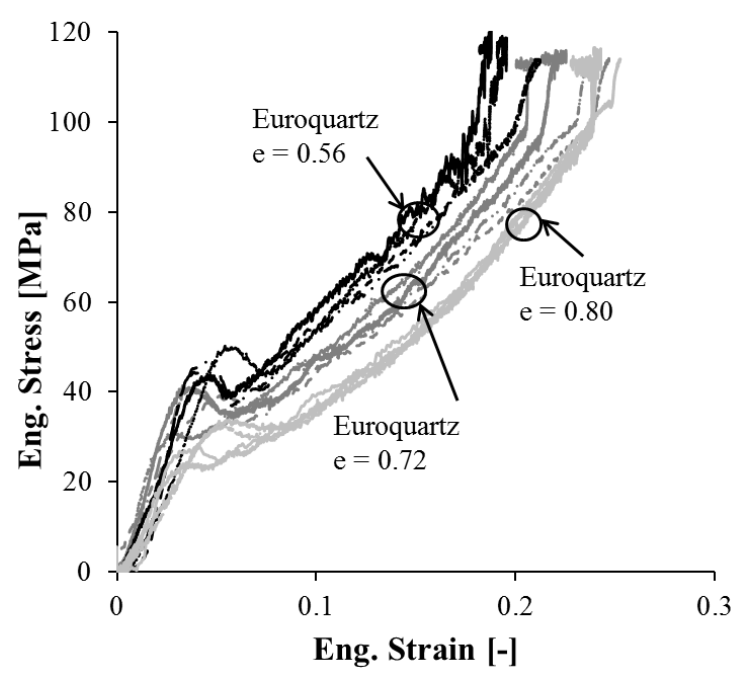

Fig. 12 Effect of the initial consolidation state on Euroquartz sand at $1600 \mathrm{~s}^{-1}$

As expected the increase in the relative density produced higher flow stresses. 
Fig. 13-a shows, for Euroquartz sand, the effect of the initial consolidation state on the confined modulus $K_{1}$. Also in this case, higher values of $K_{1}$ were obtained for samples with higher initial relative density (stiffer behavior for denser sand).

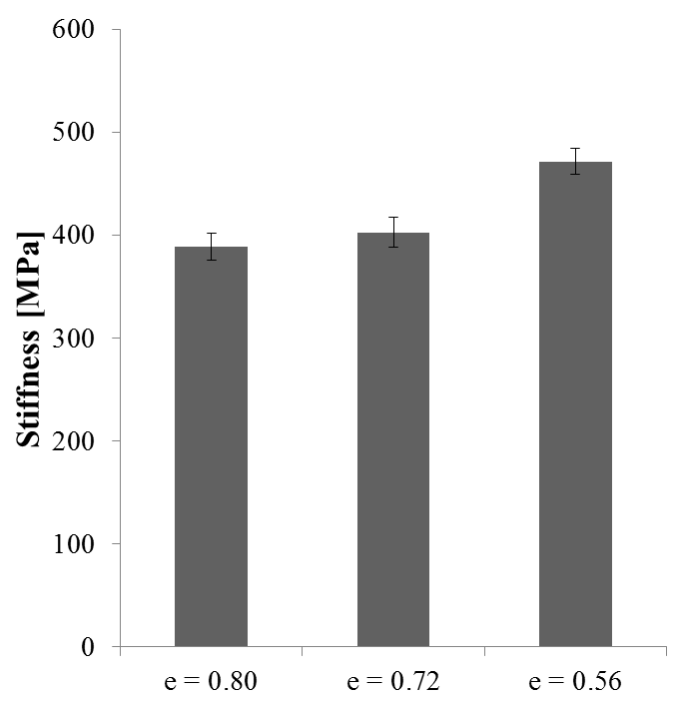

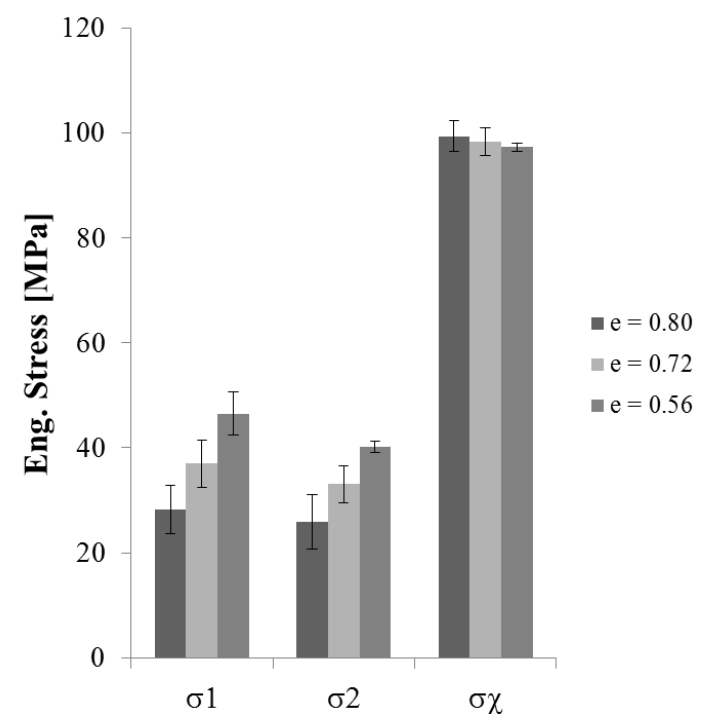

b)

a)

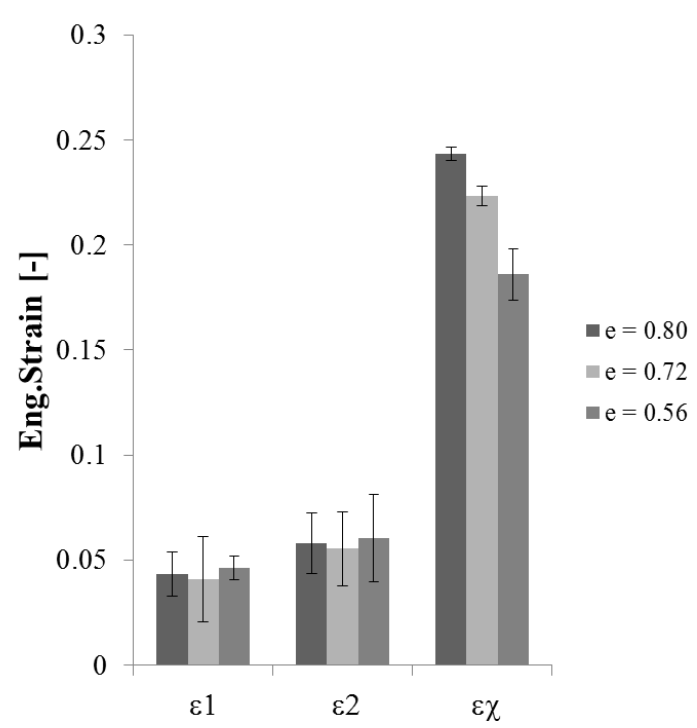

c)

Fig. 13 Confined modulus for the three initial void ratios (a) and effect of the initial consolidation state on the salient points of the stress (b) - strain (c) curves for Euroquartz sand

The point $\chi$ was characterised, for loose Euroquartz sand, by higher strains $\left(\varepsilon_{\chi}\right)$ and similar levels of stress $\left(\sigma_{\chi}\right)$ when compared to denser configurations (Fig. 13-b and Fig. 13-c). Moreover, denser samples produced higher apparent yield stresses but no significant variation in the corresponding strains.

Analogous results, but in a narrower range of strain, were found by Song et al. [20]. Also Luo et al. [30] drew similar conclusions by testing, with a conventional SHPB, Englin sand in different consolidation states, at strain rates of $600 \mathrm{~s}^{-1}$. 
Finally, a summary of the dissipated energy per unit volume corresponding to the four zones of the stress-strain curves (Fig. 6) for the three types of sand in the three different consolidation states, at a strain rate of $1600 \mathrm{~s}^{-1}$, is reported in Table 5 .

Table 5 Effect of the consolidation state on the specific energy dissipated during dynamic compression of representative samples of the three types of sand; all values are in $\mathrm{MJ} / \mathrm{m}^{3}$

\begin{tabular}{|c|c|c|c|c|c|c|c|c|c|}
\hline & \multicolumn{4}{|c|}{ Dense } & \multicolumn{3}{c|}{ Intermediate } & \multicolumn{3}{c|}{ Loose } \\
\cline { 2 - 11 } & $E_{1-2}$ & $E_{3}$ & $E_{4}$ & $E_{1-2}$ & $E_{3}$ & $E_{4}$ & $E_{1-2}$ & $E_{3}$ & $E_{4}$ \\
\hline Ottawa & 141.4 & 799.0 & 67.2 & 142.0 & 855.1 & 37.5 & 79.6 & 1001.5 & 124.4 \\
\hline Q-Rok & 121.9 & 992.4 & 194.2 & 125.0 & 1061.0 & 213.8 & 111.6 & 1075.4 & 207.4 \\
\hline Euroquartz & 151.4 & 758.6 & 169.8 & 163.8 & 760.8 & 164.7 & 22.6 & 779.9 & 64.7 \\
\hline
\end{tabular}

In all cases, the amount of energy associated to zone 1-2 and zone 4 is comparable and considerably lower than $E_{3}$. Therefore, most of the energy is released in zone 3 of the stressstrain curves, where grains rearrangement and fracture are predominant. It is also evident that this portion of energy increases, for a specific type of sand, when increasing the void ratio. This is thought to be due to a longer duration of the compaction and reorganization of sand grains because of the higher availability of voids.

Summarising, the mechanical response of dense granular material showed:

- Steeper confined modulus;

- Lower deformation at the point $\chi$;

- Higher stresses, but similar strains, at the apparent yield point;

- Lower dissipated specific energy in zone 3 of the stress-strain curve

when compared to the response of loose samples.

\subsection{EFFECT OF THE GRAIN SHAPE}

The effect of the grains morphology on the mechanical response of sand is herein addressed.

This section presents a direct comparison between Ottawa and Q-Rok sands, characterised by spherical and polyhedral grains respectively. Two different strain rates were imposed to investigate any interaction between the rate of deformation and shape of the grains on the resultant mechanical response. Samples of both types of sand were prepared with equal void ratio to eliminate any possible influence of the consolidation state on the following analysis. 
Fig. 14 shows the effect of the grain shape on the stress-strain curve at intermediate and high strain rate. The Ottawa sand, composed of spherical grains, exhibited a steeper but less extended stress-strain curve when compared to the Q-Rok sand.

In the compaction phase (zone 3 in Fig. 6), the deformation of the granular material is due mainly to the rearrangement and fracture of the grains. When a polyhedral grain is compressed, the rough edges produce a local stress concentration leading to an anticipated failure. For a spherical grain, instead, higher forces are required to reach the failure condition. Such hypothesis is confirmed by the post-mortem sieving analysis presented in Fig. 15.

Q-Rok sand shows a more pronounced comminution than Ottawa sand having the same initial consolidation state and tested in the same experimental conditions.

Thereby, the Q-Rok sand, composed of polyhedral grains, was compressed up to higher engineering strains but it was characterised by a lower flow stress when compared to the Ottawa sand. This is shown in Fig. 16-b and Fig. 16-c, where $\sigma_{2}$ and $\sigma_{\chi}$ were higher for Ottawa sand than for Q-Rok sand. On the contrary, $\varepsilon_{2}$ and $\varepsilon_{\chi}$ were higher for Q-Rok sand.

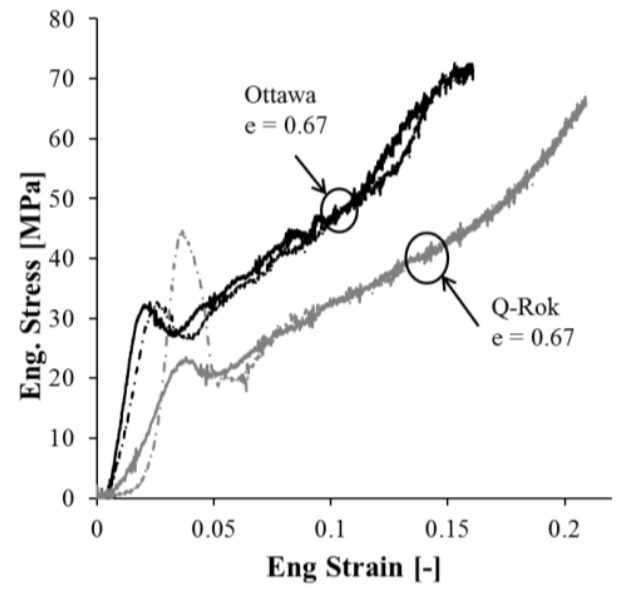

a)

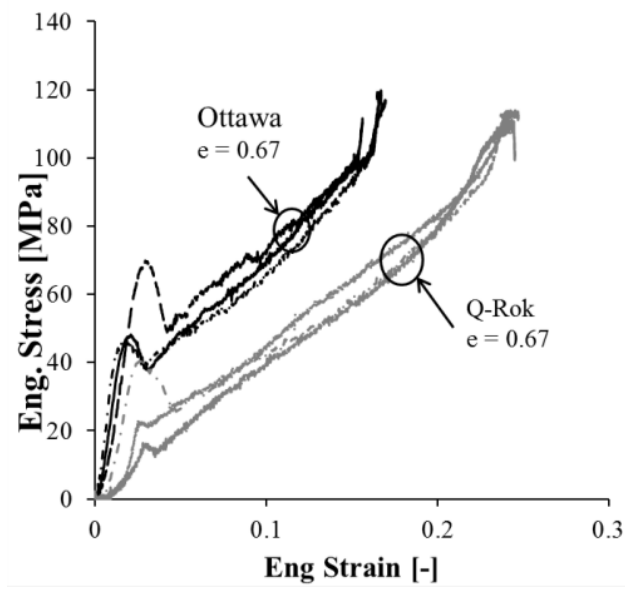

b)

Fig. 14 Effect of the grains shape at (a) $600 \mathrm{~s}^{-1}$ and (b) $1600 \mathrm{~s}^{-1}$ 


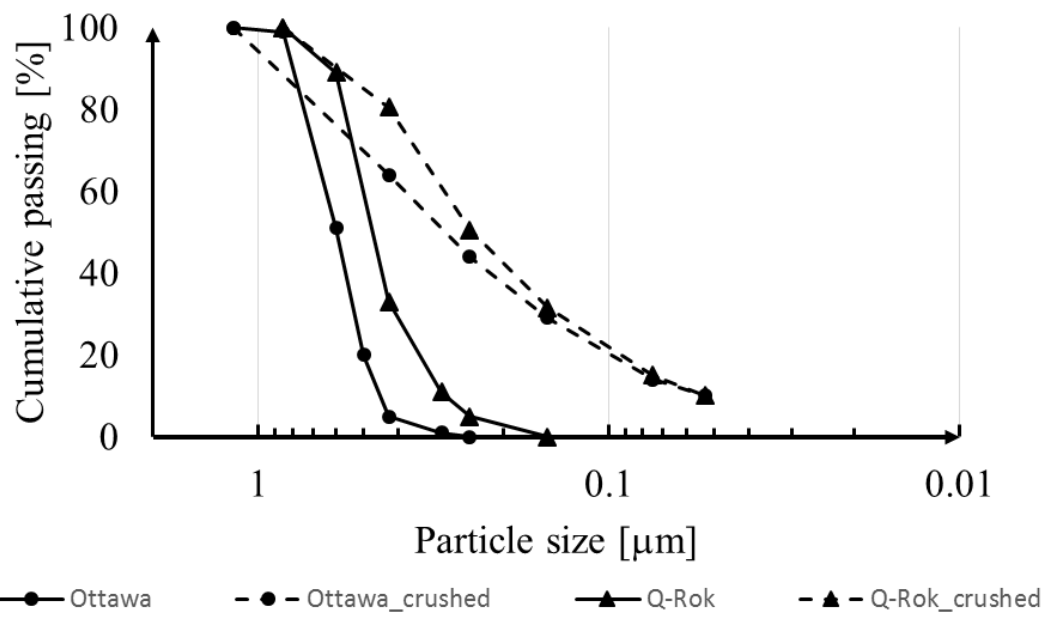

Fig. 15: Sieving analysis of Ottawa and Q-Rok sand before (continuous line) and after (dotted line) the SHPB tests

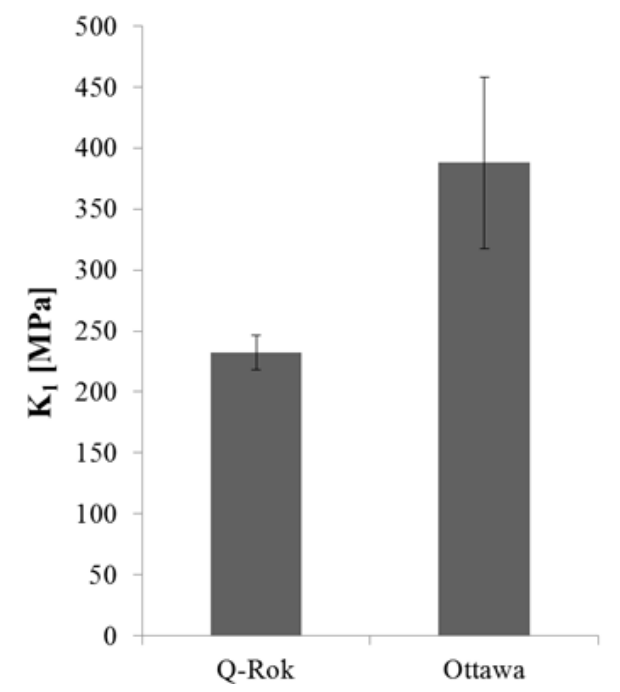

a)

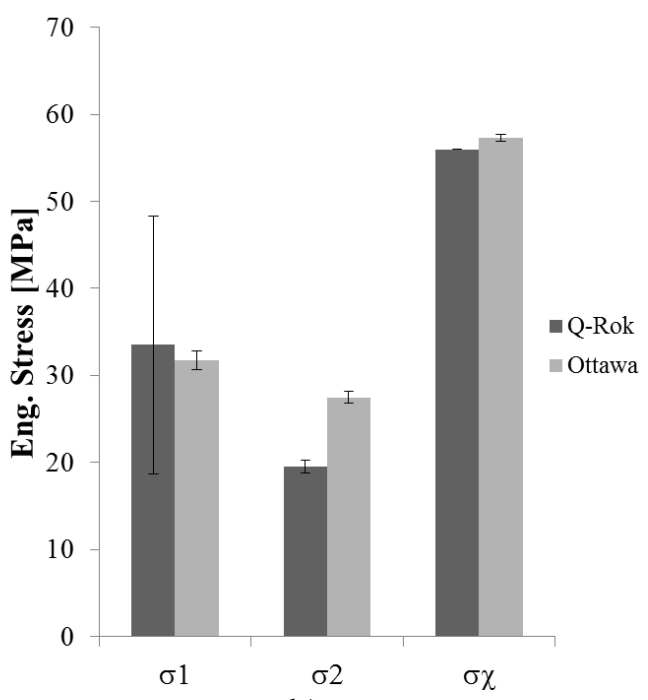

b)

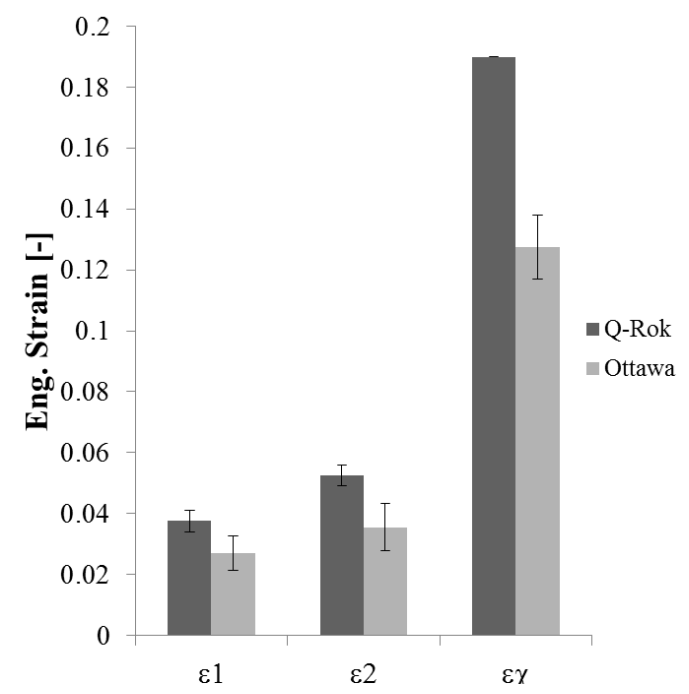

c) 
Fig. 16 Effect of the grains shape on confined modulus (a), stress (b) and strain (c) at $600 \mathrm{~s}^{-1}$

All the observations made so far on the effect of the grain shape apply also to tests conducted at higher strain rates $\left(1600 \mathrm{~s}^{-1}\right)$, as shown in Fig. 14-b, Fig. 16 and Fig. 17.

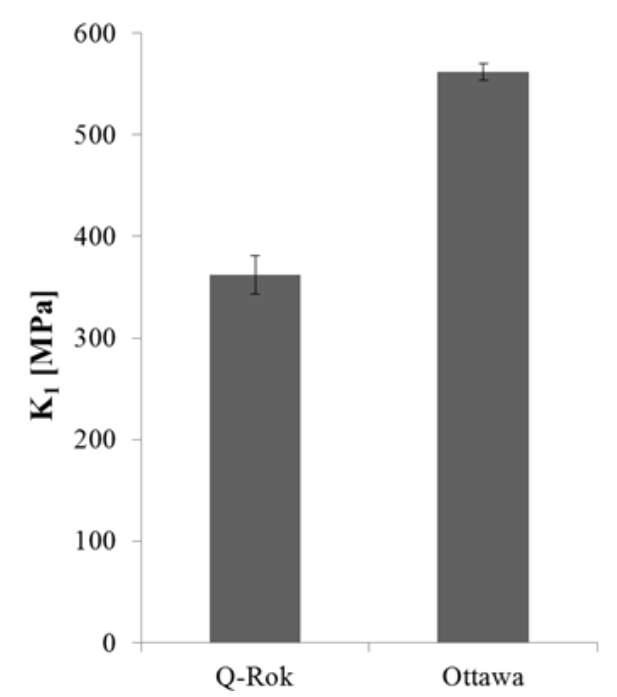

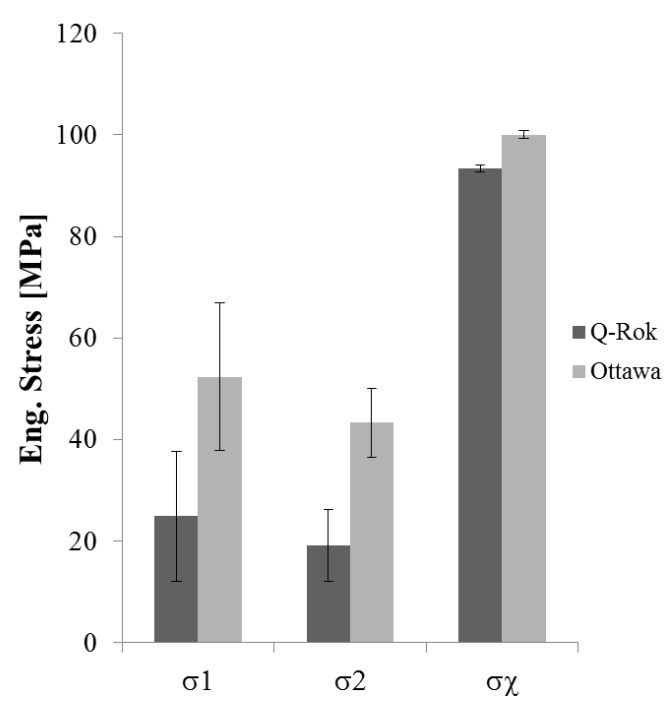

b)

a)

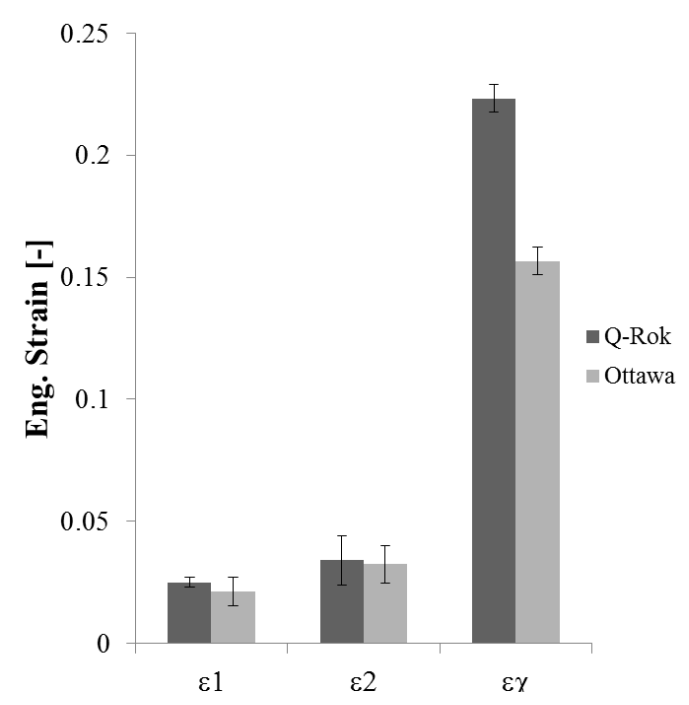

c)

Fig. 17 Effect of the grain shapes on confined modulus (a), stress (b) and strain (c) at 1600/s

Table 6 shows the energy dissipated during uniaxial compression of the two types of sand at a strain rate of $1600 \mathrm{~s}^{-1}$ (Fig. 14-b). The specific energy dissipated in zone 3 and 4 in case of sand with polyhedral grains (Q-Rok) was higher than what measured for sand with spherical particles. This is believed to be a consequence of the increased propensity to failure of polyhedral grains. An opposite trend was measured, instead, for $E_{1-2}$. 
Table 6 Effect of the grain shapes on the specific energy dissipated during uniaxial compression of representative samples; all values are in $\mathrm{MJ} / \mathrm{m} 3$

\begin{tabular}{|c|c|c|c|}
\hline & $E_{1-2}$ & $E_{3}$ & $E_{4}$ \\
\hline Ottawa & 142.0 & 855.1 & 37.5 \\
\hline Q-Rok & 121.9 & 992.4 & 194.2 \\
\hline
\end{tabular}

In conclusion, sands with spherical grains can withstand higher levels of stress while undergoing lower deformations compared to sands with polyhedral grains. This effect is mainly due to the fracture of grains that is strongly dependent on the grain shape $[31,28]$, as confirmed by the different energy dissipation in zone 3 and 4 . These results are in line with what presented by Omidivar et al. [16] and Wang et al. [32]. In particular, the latter work showed the effect of the grains shape on the mechanical behaviour of granular materials by comparing real sand, composed of grains with irregular shapes, with perfectly spherical glass beads.

\subsection{EFFECT OF COATING AND INTER-GRANULAR FRICTION}

The mechanical behavior of sand under quasi-uniaxial strain compressive loading is also influenced by the surface properties of the grains as they mutually interact through contact. Therefore, the influence of the grains surface properties on the overall response of the material needs to be addressed.

In this section, the stress-strain curves obtained from natural Euroquartz sand are compared with those obtained testing coated Euroquartz sand. The grains were coated using a thin and uniform layer of epoxy resin. After being coated, the sand was dried in an oven at $100^{\circ} \mathrm{C}$ for 24 hours before testing.

Fig. 18 shows the effect of the drying process on the response of dense coated Euroquartz sand. 


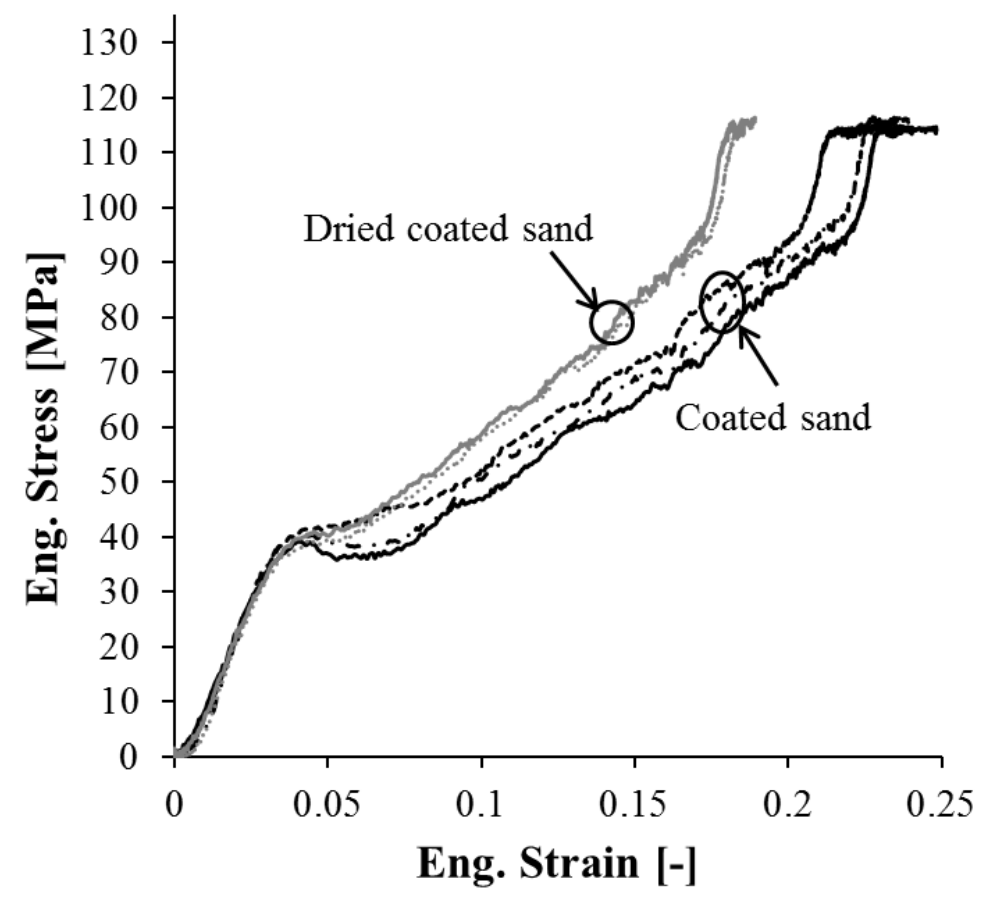

Fig. 18 Effect of the drying process on the dense coated Euroquartz sand at high strain rate

When dried, the coating undergoes a change of its material properties (epoxy resin softens with temperature above glass transition) that results in the modification of the overall response of the granular assembly. The variation in the confined modulus due to the drying process was evident.

The diagram shown in Fig. 19-a quantifies the increase of K1 when the coated sand was dried. The drying process resulted in a reduction of the maximum deformation but it did not affect the measured stresses (Fig. 19-b and Fig. 19-c). This behaviour could be explained by the variation of the surface properties of the grains due to the heating process.

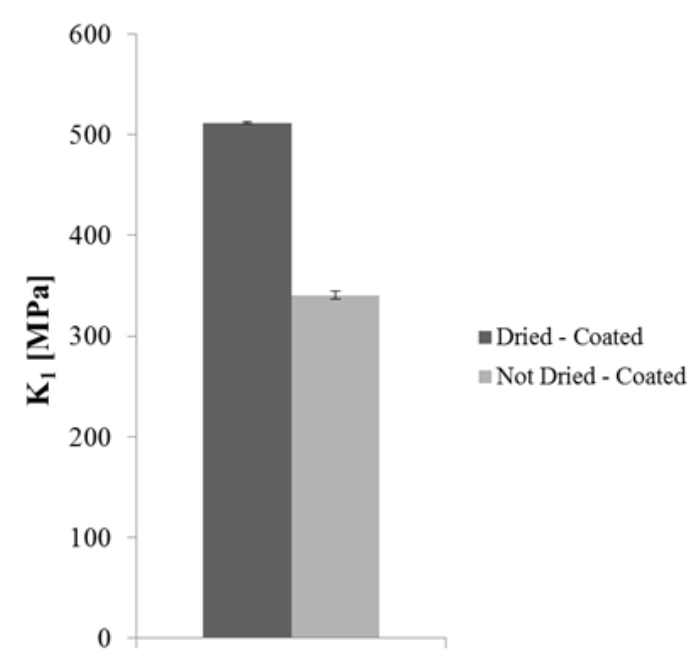

a) 


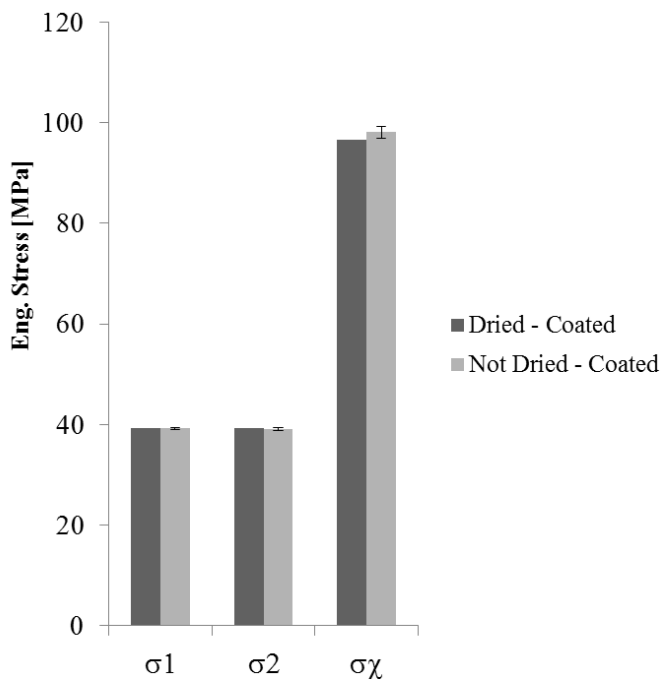

b)

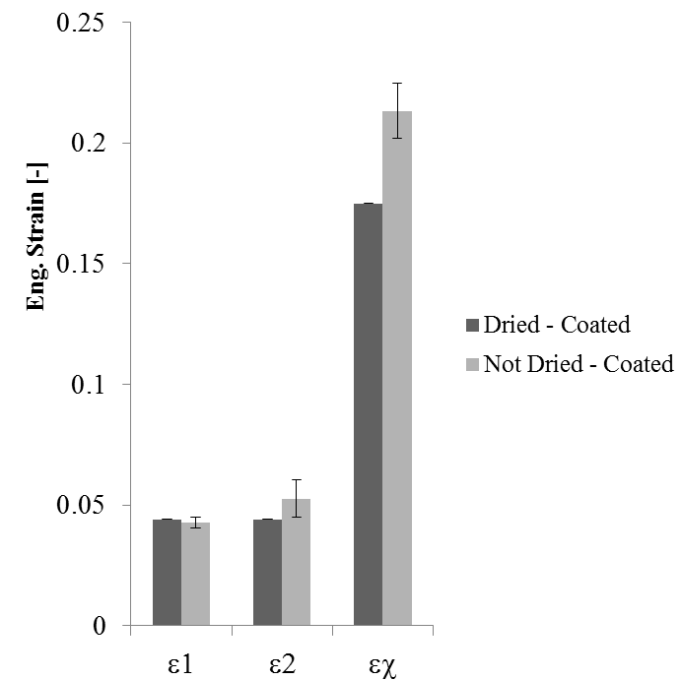

c)

Fig. 19 Effect of the drying process on confined modulus (a), stress (b) and strain (c) for coated Euroquartz sand

Following, the behaviour of dried coated sand was compared to the natural occurring sand in order to appreciate the combination of the effects of surface properties and initial consolidation state. Fig. 20-a compares the mechanical response of natural and coated Euroquartz sand in a dense initial configuration.

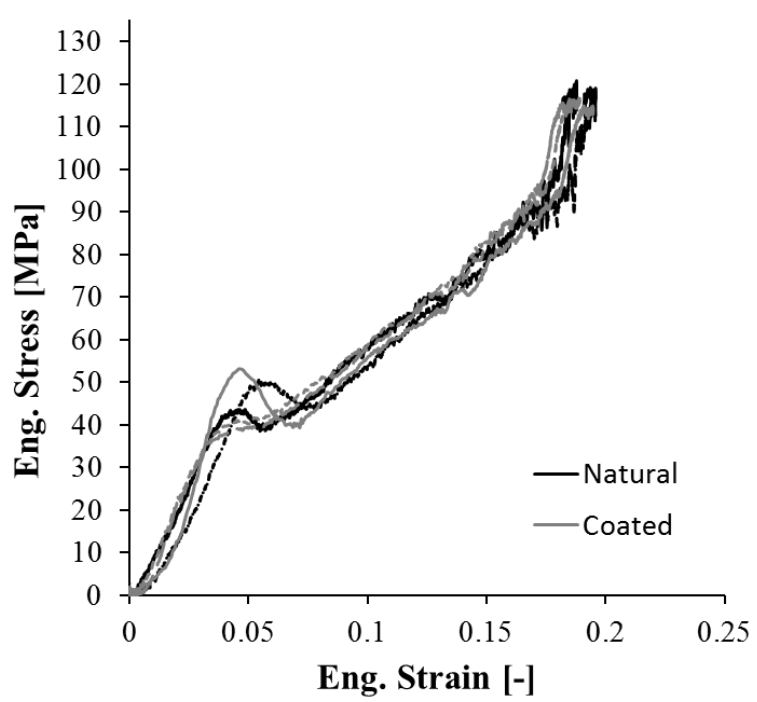

a)

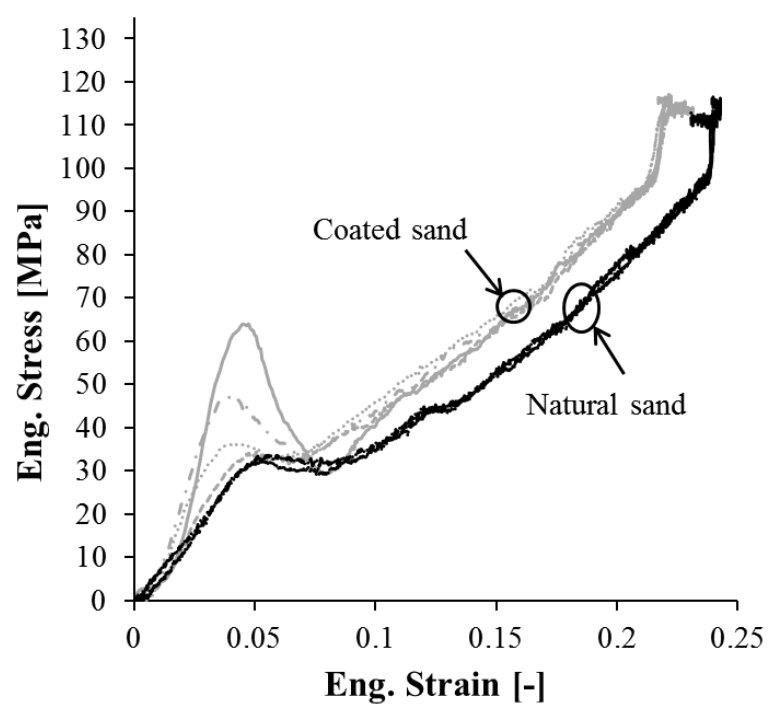

b)

Fig. 20 Effect of coating on (a) dense and (b) loose Euroquartz sand

When the sand was tightly packed, the variation of surface properties did not influence its mechanical response.

Fig. 20-b, instead, presents the effect of the coating on the response of Euroquartz sand in a loose consolidation state. In this case, the effect was noticeable. The coating induced an 
increase in the confined modulus of the sand making it less compliant in compression (Fig. 21a).

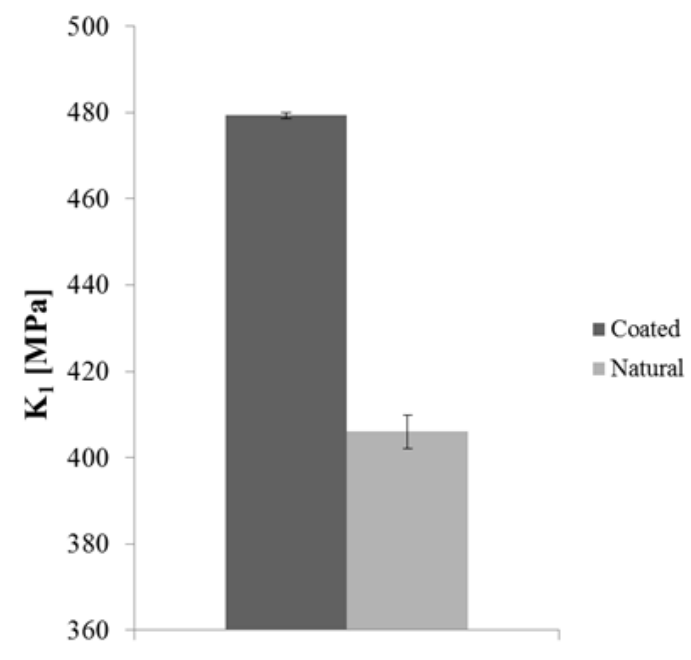

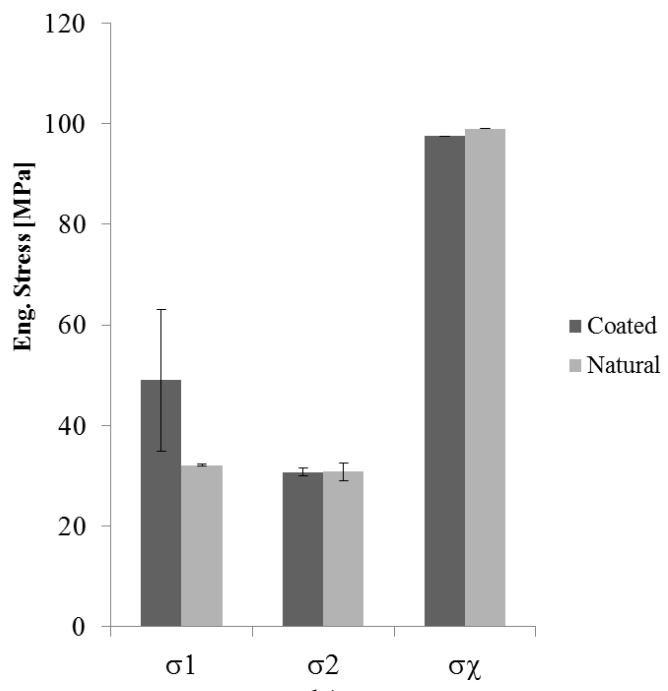

b)

a)

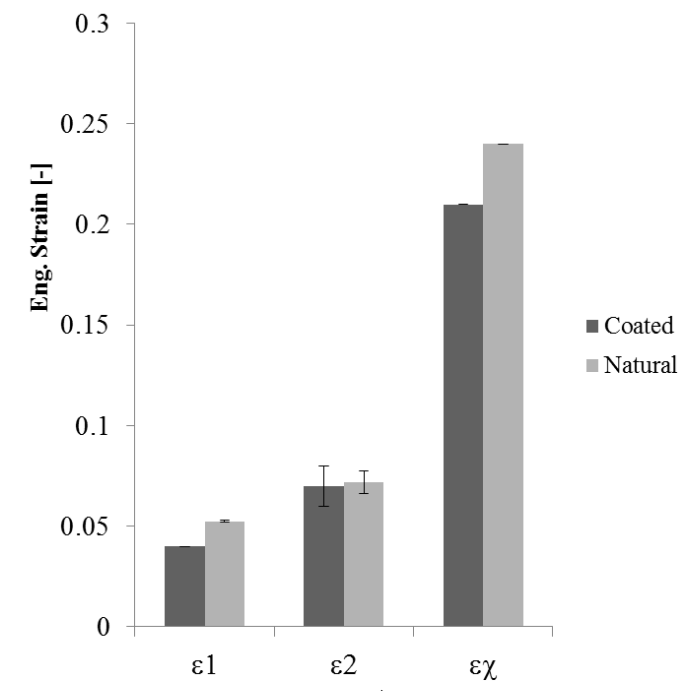

c)

Fig. 21 Effect of coating on (a) confined modulus, (b) stress and (c) strain of loose Euroquartz sand

The coating produced a general stiffening of the mechanical response. Hence, at equal loading conditions the coated sand was characterised by lower compression strain. However, there was no significant variation in the characteristic stress levels (Fig. 21-b and Fig. 21-c). This behaviour could be explained by the increase of intergranular friction due to the presence of the coating. 
Table 7 Effect of inter-granular friction on the specific energy dissipated during uniaxial compression of representative samples; all values are in $\mathrm{MJ} / \mathrm{m} 3$

\begin{tabular}{|c|c|c|c|}
\hline & $E_{1-2}$ & $E_{3}$ & $E_{4}$ \\
\hline Natural & 22.6 & 679.9 & 124.7 \\
\hline Coated & 150 & 809.5 & 275.2 \\
\hline
\end{tabular}

Table 7 summarises the specific energy dissipated when compressing natural or coated Euroquartz sand in a loose initial consolidation state (Fig. 20-b). The introduction of additional inter-granular friction due to the coating increased the amount of energy dissipated in all zones of the stress-strain curves.

Summarising, the aforementioned results show, for the first time in literature, that the surface properties of the grains affect the response of the sand under compressive loading in quasiuniaxial strain conditions. The effect of friction was only evident in loose configurations, having the grains more freedom of movement than in dense packing configurations. The increase of friction enhanced the inter-granular locking, producing an increase in the stiffness of the material (during the compaction phase) and a reduction of the maximum compression strain.

\subsection{EFFECT OF THE CONFINEMENT}

The investigation of the compressive mechanical behaviour of granular materials under quasiuniaxial stress conditions requires the use of containments opposing negligible resistance to radial deformations. Latex confinements (described in detail in Section 2.2.2) were used for this purpose. In this case, the sand was free to expand radially because of the very low resistance imposed by the latex to radial deformations (low confining pressures). 


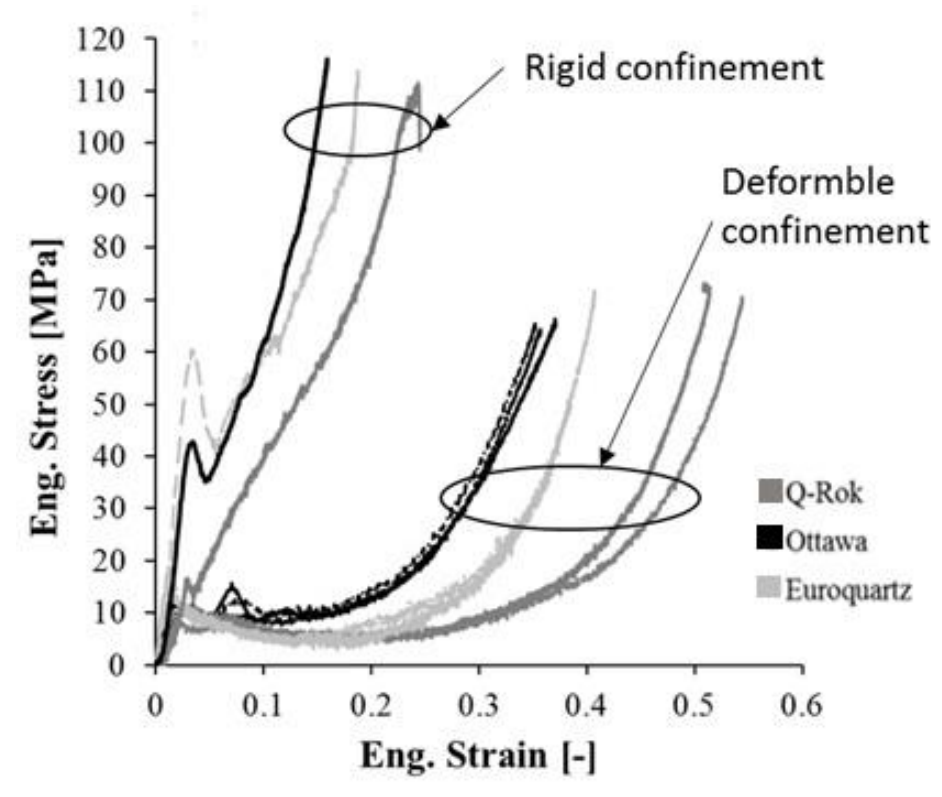

Fig. 22 Effect of the deformable confinement on the response of the three types of sand at 1000/s

Fig. 22 shows the comparison between the experimental results obtained on three types of sand, in a dense compaction state, compressed at a strain rate of $1000 \mathrm{~s}^{-1}$ using rigid (quasi-uniaxial strain) and deformable containers (quasi-uniaxial stress).

Q-Rok sand was more compliant than the other two types of sand in both conditions. Ottawa and Euroquartz sands presented same levels of stress for strains lower than 0.1, regardless the type of confinement adopted. At higher strains, Ottawa sand exhibited a higher flow stress then Euroquartz sand.

The compressive stress-strain behaviour of sand confined in deformable containers appeared to be very different with respect to the one constrained in a rigid confinement. The initial pseudo-elastic response, due to the elastic recoverable deformation of the grains, was similar in both configurations. Also, the position of the apparent yield point was unaffected by the type of confinement. Therefore, for very low deformations the mechanical behaviour was not influenced by the confining pressure.

For engineering strains larger than 5\%, the sand tested in a quasi-uniaxial stress condition exhibited lower flow stresses when compared to the sand constrained into a rigid confinement.

Fig. 23 shows the relevant stress and strain values for the three types of sand investigated, confined in deformable containers. The adoption of the LSHPB allowed for the achievement 
of larger deformations, thus speculating the compressive behaviour of the sand at strains higher than those usually achieved in literature.

The type of confinement affected the confined modulus, as this portion of the stress-strain curve depends upon the reorganisation of the grains and on their fragmentation. The reduction of the confining pressure modified the reorganisation process and, consequently, the overall behaviour. For engineering strains larger than $\varepsilon_{\chi}$ the slope of the curves exhibited an upsurge, with stiffness similar to the stiffness of the initial pseudo-elastic response (zone 1 in Fig. 6). This could be due to the fragmentation of the grains during compression. At this stage, most of the grains are plausibly fractured. Consequently, the response of the sand becomes equivalent to the response of an assembly of much smaller grains, able to sustain larger stresses without further comminution (size effect).
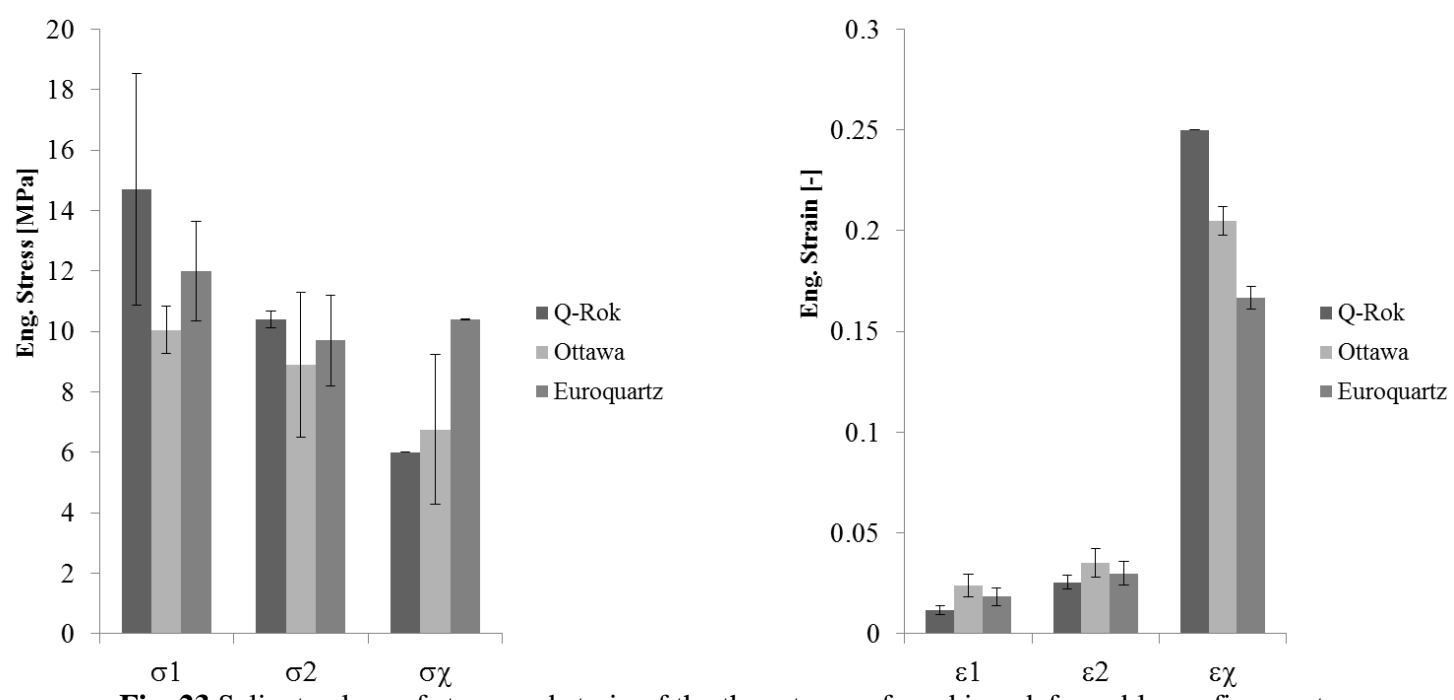

Fig. 23 Salient values of stress and strain of the three types of sand in a deformable confinement

In conclusion, the variation of the type of confinement heavily modified the mechanical behaviour of granular materials. The adoption of deformable containers allowed for lateral deformation, thus producing test conditions similar to those obtained in quasi-uniaxial stress conditions. The effect of using a highly deformable confinement was evident in zone 3 and zone 4 of the stress-strain curves (Fig. 11). In zone 3, the response deviated from the lock-up behaviour shown in the case of rigid confinements. As the level of confining pressure reduced, the soil sustained less axial stress. At large strains, a steep increase in the levels of stresses was observed. Omidvar et al. [16] and Song et al. [20] obtained analogous results using slightly stiffer lateral confinements (e.g. polyolefin heat shrinking tube). Similarly, Martin et al. [33] identified an increased material strength when testing granular samples, at higher confining pressure, using a modified Kolsky bar capable of applying triaxial loading. Moreover, 
Pellegrino et al. [22] identified a similar behaviour in volcanic ashes, confined in latex containers and subjected to impact loading.

Table 8 reports the specific energies for the three types of sand in deformable and rigid confinements (Fig. 22).

Table 8 Effect of confinement on the specific energy dissipated during uniaxial compression of representative samples; all values are in $\mathrm{MJ} / \mathrm{m} 3$

\begin{tabular}{|c|c|c|c|c|c|c|}
\hline \multirow{2}{*}{} & \multicolumn{3}{|c|}{ Deformable } & \multicolumn{3}{c|}{ Rigid } \\
\cline { 2 - 7 } & $E_{1-2}$ & $E_{3}$ & $E_{4}$ & $E_{1-2}$ & $E_{3}$ & $E_{4}$ \\
\hline Ottawa & 11.8 & 158.0 & 240.5 & 141.4 & 799.0 & 67.5 \\
\hline Euroquartz & 47.9 & 139.1 & 492.2 & 151.4 & 758.6 & 169.8 \\
\hline Q-Rok & 18.8 & 120.0 & 538.8 & 121.9 & 992.4 & 194.2 \\
\hline
\end{tabular}

Differently from sand confined in rigid containers, the adoption of deformable confinements resulted in higher specific energy dissipation in zone 4 than in zone 3. Moreover, also in the case of deformable containers, the effect of the grain shapes on the energy dissipation was evident, as $E_{4}$ increased going from Ottawa (with spherical grains) to Q-Rok sand (with polyhedral grains). This is believed to be a consequence of the increased propensity to failure of polyhedral grains.

\subsection{COMBINED EFFECT OF STRAIN RATE, SHAPE AND CONFINEMENT}

This section presents the combined effects of strain rate and grain morphology on the mechanical response of different types of sand in deformable confinements. To understand the effects of the strain rate on the mechanical behaviour of sand, each type of sand investigated in the present study was tested at two different strain rates in quasi-uniaxial stress conditions.

Fig. 24-a shows that the effect of the strain rate on the compressive mechanical response of QRok sand, contained in a deformable confinement, was negligible. However, the apparent yield stress increased noticeably with increasing strain rates as outlined in Fig. 25. 


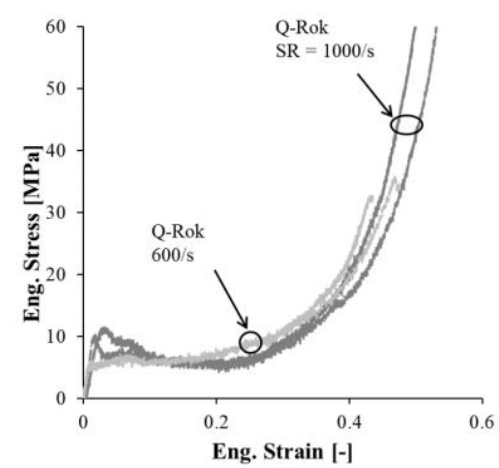

a)

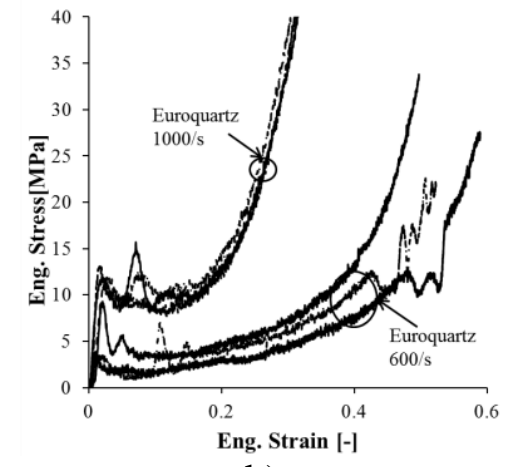

b)

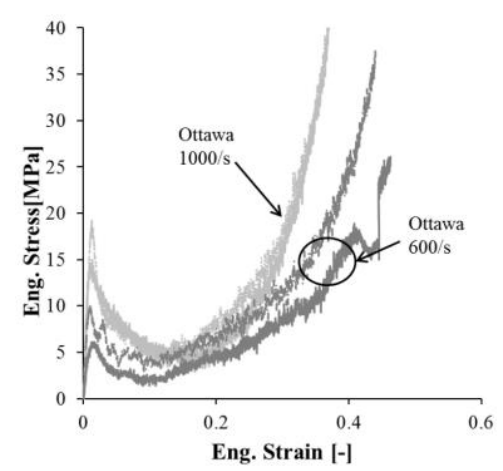

c)

Fig. 24 Effect of the strain rate on the mechanical behaviour of (a) dense Q-Rok, (b) Euroquartz and (c) Ottawa sand in deformable containers

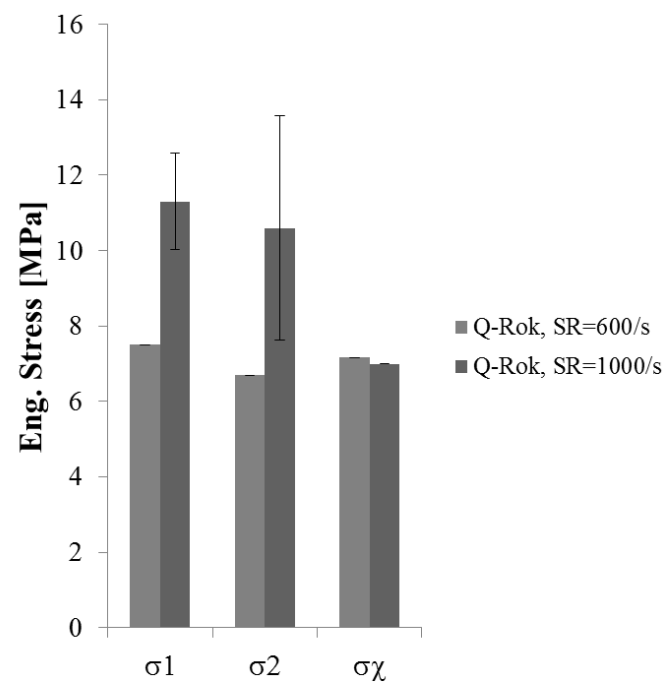

Fig. 25 Example showing the effect of the strain rate on the values of stress of dense Q-Rok sand in deformable containers

Fig. 24-b shows the effect of the strain rate on Euroquartz sand constrained in a deformable confinement. It is evident that the increase of strain rate produced a stronger mechanical response. Fig. 24-c shows the rate dependence of Ottawa sand characterised using the same type of confinement. The variation due to the strain rate is less evident than for Euroquartz sand. Nevertheless, also in this case, the increase of strain rate produced a slightly higher mechanical response.

Table 9 Effect of strain rate and confinement on the specific energy dissipated during uniaxial compression of representative samples; all values are in $\mathrm{MJ} / \mathrm{m} 3$

\begin{tabular}{|c|c|c|c|c|c|c|}
\hline & \multicolumn{3}{|c|}{$600 \mathrm{~s}^{-1}$} & \multicolumn{3}{c|}{$1000 \mathrm{~s}^{-1}$} \\
\cline { 2 - 7 } & $E_{1-2}$ & $E_{3}$ & $E_{4}$ & $E_{1-2}$ & $E_{3}$ & $E_{4}$ \\
\hline Ottawa & 5.5 & 153.1 & 193.9 & 11.8 & 171.5 & 295 \\
\hline Euroquartz & 12.9 & 124.5 & 214.2 & 68.4 & 198.9 & 438.7 \\
\hline Q-Rok & 56.6 & 141 & 258 & 44.1 & 276.6 & 474.7 \\
\hline
\end{tabular}


Table 9 demonstrates that an increase of strain rate resulted in higher values of specific dissipated energy in zone 4 for all types of sand. The effects of grain shape on the dissipated energy shown in Table 8 is confirmed by the values of $E_{4}$ reported in Table 9.

Fig. 26 compares the results obtained on the three types of sand at a strain rate of $600 \mathrm{~s}^{-1}$, thus confirming the influence of the grain shape on the mechanical behaviour of sand enclosed in deformable containers.

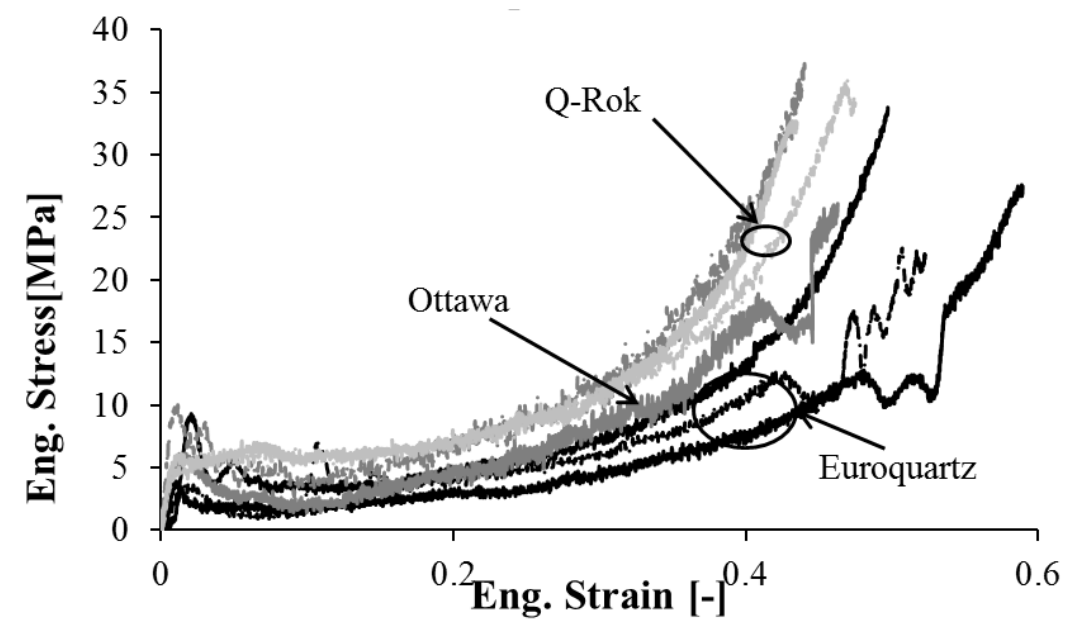

Fig. 26 Combined effects of shape and confinement at a lower strain rate

In conclusion, an increase in the strain rate was always accompanied by an increase of strength in the mechanical response of sand confined in deformable containers. Similar conclusions can be also found in [16]. However, the observed rate dependence was different for different types of sand (i.e. for different grain shapes). The compressive behaviour of sand is strongly dependent upon the rearrangement of grains and on their fracture. The variation of the measured stress-strain curves with the rate of deformation and with grain shape demonstrated the strong influence of both these parameters on grain fracture and rearrangement.

\section{CONCLUSIONS}

The research herein presented provides a comprehensive study of the effects of several parameters and their cross-interaction on the mechanical response of sand under dynamic uniaxial loading conditions. The effects of initial consolidation state, confining pressure, strain rate, intergranular friction and morphology were investigated.

All experiments were carried out using the Long Split Hopkinson Pressure Bar apparatus, thus allowing for the achievement of longer pulse durations and higher strains. 
The effect of initial consolidation state was assessed using three different preparation procedures to prepare loose, intermediate and dense samples. Three different types of sand were tested at two different strain rates to determine any possible interaction between initial compaction, grain shape and strain rate. The results showed a noticeable stiffening of the stressstrain curves with the increase of the initial density, regardless the grain shape and the strain rate.

The concurrent effects of grain morphology and strain rate were observed comparing the mechanical response of Ottawa sand (with quasi-spherical particles) and Q-Rok (with polyhedral grains) at two different strain rates. The sand composed of spherical grains was characterised by a higher stress-strain relationship when compared to sands composed of polyhedral grains. This is thought to be a consequence of the grain fracturing mechanisms, which, in turn, depend upon the grain shape.

The authors, for the first time in literature, showed the effect of intra-granular friction on the mechanical response of granular materials comparing the behaviour of naturally occurring and coated Euroquartz sand. The effect of the coating depended considerably upon the initial consolidation state. When the sand was tightly packed, the variation of surface properties did not seem to influence its mechanical response. The effect of the coating was more evident in loose configurations where the grains, when compressed, had more freedom of movement. The increase of friction due to the coating enhanced the inter-granular locking, hence increasing the stiffness of the material and reducing the maximum compressive strains.

The effect of the confining pressure was also analysed. The adoption of latex confinements allowed the sand to expand radially because of their very low resistance to radial stresses. This configuration generated quasi-uniaxial stress conditions during testing. The initial pseudoelastic response was not affected by the confining pressure. The type of container affected, instead, the confined modulus. This indicated a strong effect of the confining pressure on the reorganisation of the grains and on their fracture during uniaxial compression. The strain rate sensitivity of the sand in quasi-uniaxial stress condition was strongly dependent upon the shape of the grains. An increase in the strain rate always yielded a stronger material response and a higher apparent yield point when testing sand in deformable containers. This demonstrated the interdependence of confining pressure and grains morphology on their fracture and rearrangement. 
Future research, by means of experimental and numerical speculations, should focus on the understanding of micromechanical phenomena occurring in granular materials during compression such as intergranular friction, grain fracture and their rate dependence.

\section{ACKNOWLEDGMENTS}

The authors gratefully acknowledge the support of the Defense Threat Reduction Agency (DTRA), Grant No: HDTRA1-12-1-0045. The authors would also like to thank Dr. Felix Kim and Mr. Aashish Sharma at the University of Tennessee and Mr Jeffrey Fullerton and Mr Stuart Carter at Oxford for their assistance with fixture preparation and experimental setup and Mrs Karen Bamford for her continuous support.

\section{REFERENCES}

[1] J. Zhang, "Transient shear strength of saturated sand under cyclic loading considering strain-rate effect," Soil and Foundations, vol. 34, pp. 51-65, 1994.

[2] J. An, Soil behaviour under blast loading, Lincoln, USA: PhD Thesis, University of Nebraska , 2010.

[3] J. L. Brown, T. J. Vogler, L. C. Chhabildas, W. D. Reinhart and T. F. Thornhill, "Shock response of dry sand. SAND2007-3524," Sandia National Laboratories, 2007.

[4] J. Borg and T. Vogler, "An Experimental Investigation of the a High Velocity Projectile Penetrating Sand," in SEM XI International Congress \& Exposition on Experimental \& Applied Mechanics, Orlando, Florida, USA, 2008.

[5] W. Chen and B. Song, "Split - Hopkinson (Kolsky) bar: design; testing and applications," Springer, 2011.

[6] J. Field, S. Walley, W. Proud, H. Goldrein and C. Siviour, "Review of experimental techniques for high rate deformation and shock studies," International Journal of Impact Engineering, vol. 30, pp. 725-775, 2004. 
[7] H. Kolsky, "An investigation of the mechanical properties of materials at very high rates of loading," Proceedings of the Physical Society. Section B, vol. 62, no. 11, p. 676, 1949.

[8] G. Gray, "ASM Handbook: Mechanical Testing and Evaluation," Materials Park, Ohio, ASM International, 2000, pp. 462-476.

[9] W. Charlie, C. Ross and S. Pierce, "Split-Hopkinson Pressure Bar Testing of Unsaturated Sand," Geotechnical Testing Journal, vol. 13 (4), pp. 291-300, 1990.

[10] D. J. F. Frew and W. Chen, "Pulse Shaping Techniques for Testing Brittle Materials with a Split - Hopkinson Pressure Bar," Experimental Mechanics, vol. 42(1), pp. 93-106, 2002.

[11] J. Parry, A. Walker and P. R. Dixon, "Hopkinson bar pulse smoothing," Meas. Sci. Technol., vol. 443, no. 6, pp. 443--446, 1995.

[12] M. Scheidler, J. Fitzpatrick and R. Kraft, "Optimal pulse shapes for SHPB tests on soft materials," in Proceedings of the 2011 SEM Annual Conference and Exposition on Experimental and Applied Mechanics, Uncasville, CT, 2011.

[13] F. De Cola, A. Pellegrino, E. Barbieri, D. Penumadu and N. Petrinic, "Void ratio based representative volume element for modelling the high strain rate behaviour of granular materials," International Journal of Impact Engineering, vol. 91, pp. 46-55, 2016.

[14] R. Gerlach, C. Kettenbeil and N. Petrinic, "A new split - Hopkinson tensile bar design," International Journal of Impact Engineering, vol. 50, pp. 63-67, 2012.

[15] B. Andreotti, Y. Forterre and O. Pouliquen, Granular Media: Between Fluid and Solid, Cambridge University Press, 2013.

[16] M. Omidvar, M. Iskander and S. Bless, "Stress-strain behavior of sand at high strain rates," International Journal of Impact Engineering, vol. 49, pp. 192-213, 2012.

[17] A. Bragov, V. Balandin, A. Lomunov and A. Filippov, "Determining the impact compressibility of soft soils from inversed test results," Technical physics letters, vol. 32, no. 6, pp. 487--488, 2006. 
[18] A. Bragov, G. Grushevsky and A. Lomunov, "Use of the Kolsky method for confined tests of soft soils," Experimental Mechanics, vol. 36, no. 3, pp. 237-242, 1996.

[19] E. Suescun-Florez, S. Kashuk, M. Iskander and S. Bless, "Predicting the Uniaxial Compressive Response of Granular Media over a wide range of tsrain rates using the strain energy density concept," Journal of dynamic behavior of materials, vol. 1, no. 3, pp. 330-346, 2015.

[20] B. Song, W. Chen and V. Luk, "Impact compressive response of dry sand," Mechanics of Materials, vol. 41, pp. 777-785, 2009.

[21] C. W. Felice, E. S. Gaffney and J. A. Brown, "Extended split Hopkinson bar analysis for attenuating materials," Jal of Engineering Mechanics, ASCE, vol. 117, pp. 1119-1135, 1991.

[22] A. Pellegrino, F. De Cola, K. Dragnevski and N. Petrinic, "The Dynamic Response of Etnean Sand and the Effect of Its Impingement on Ti-6Al-4 V Alloy," Journal of Dynamic Behavior of Materials, pp. 1-14, 2016.

[23] M. Kabir, B. Song, B. Martin and W. Chen, "Compressive behavior of fine sand," Sandia National Laboratories, Albuquerque, New Mexico, 2010.

[24] J. Santamarina and G. Cho, "Soil behaviour: the role of particle shape," in Proc. Advances in Geotechnical Engineering; The Skempton Conference, 2004.

[25] H. White and S. Walton, "Particle packing and particle shape.," J. Am. Ceram. Soc., vol. 20, 1937.

[26] P. Lade, C. Liggio and J. Yamamuro, "Effects of Non-Plastic Fines on Minimum and Maximum Void Ratio," Geotechnical Testing Journal, vol. 21, no. 4, pp. 336-347, 1998.

[27] F. Kim, D. Penumadu, J. Gregor, M. Marsh, N. Kardjilov and I. Manke, "Characterizing Partially Saturated Compacted-Sand Specimen Using 3D Image Registration of High_Resolution Neutron and X-Ray Tomography," Journal of Computing in Civil Engineering, vol. 29, no. 6, p. 04014096, 2014. 
[28] M. M. Hagerty, D. R. Hite, C. R. Ullrich and D. J. Hagerty, "One-dimensional highpressure compression of granular media," Geotech. Engrg., vol. 119, no. 1, pp. 1--18, 1993.

[29] B. E. Martin, W. Chen, B. Song and A. S. A, "Moisture effects on the high strain-rate behavior of sand," Mechanics of Material, vol. 41(6), pp. 786-798, 2009.

[30] H. Luo, H. Lu, L. Cooper and R. Komanduri, "Effect of Mass Density on the Compressive Behavior of Dry Sand Under Confinement at High Strain Rates," Experimental Mechanics, vol. 51, pp. 1499-1510, 2011.

[31] R. H. Brzesowsky, C. J. Spiers, C. J. S. Peach and J. T. Hangx, "Failure behavior of single sand grains: Theory versus experiment.," Journal of geophysical research, vol. 116, 2011.

[32] S. Wang, L. Shen, F. Maggi, A. El-Zein and G. D. Nguyen, "Uniaxial compressive behavior of partially saturated granular media under high strain rates," International Journal of Impact Engineering, vol. 102, pp. 156-168, 2017.

[33] B. Martin, M. E. Kabir and W. Chen, "Undrained high-pressure and high strain-rate response of dry sand under triaxial loading," International Journal of Impact Engineering, vol. 54, pp. 51-63, 2013. 